Western\&Graduate\&PostdoctoralStudies

Western University

Scholarship@Western

Electronic Thesis and Dissertation Repository

7-19-2017 12:00 AM

\title{
Impact of Islamophobia on Post-Secondary Muslim Students Attending Ontario Universities
}

\author{
Hassina Alizai, The University of Western Ontario \\ Supervisor: Goli Rezai-Rashti, The University of Western Ontario \\ A thesis submitted in partial fulfillment of the requirements for the Master of Education degree \\ in Education \\ (C) Hassina Alizai 2017
}

Follow this and additional works at: https://ir.lib.uwo.ca/etd

Part of the Educational Leadership Commons, Higher Education Commons, Islamic Studies Commons, Race, Ethnicity and Post-Colonial Studies Commons, and the Women's Studies Commons

\section{Recommended Citation}

Alizai, Hassina, "Impact of Islamophobia on Post-Secondary Muslim Students Attending Ontario Universities" (2017). Electronic Thesis and Dissertation Repository. 4716.

https://ir.lib.uwo.ca/etd/4716

This Dissertation/Thesis is brought to you for free and open access by Scholarship@Western. It has been accepted for inclusion in Electronic Thesis and Dissertation Repository by an authorized administrator of Scholarship@Western. For more information, please contact wlswadmin@uwo.ca. 


\begin{abstract}
This study investigated the experiences of Muslim Canadian students attending institutions of higher education in the context of increasing Islamophobia. This study utilized qualitative case study methodology to investigate the following questions: (1) What are the experiences of Muslim Canadians attending institutions of higher education in the current context of Islamophobia? (2) How is the rising anti-Muslim sentiment impacting the academic performance of Muslim students? (3) How do Muslim students negotiate or navigate their identities subsequent to recent national and international tragic events (e.g. Paris Attacks, San Bernardino and other terrorist atrocities)? The students' responses resulted in three major themes that included: (a) Islamophobia on Campus; (b) Strong religious identity, and Resisting and challenging Islamophobic sentiments; (c) Gendered Islamophobia. The findings of this research indicate that Muslim students have more attachment to their religious identity, are at the forefront of advocating for Muslims and are actively working to demystify Islamophobic notions.
\end{abstract}

\title{
Keywords
}

Islamophobia, Muslim, hijab, higher education, religious identity, resistance, advocate. 


\section{Acknowledgments}

I would like to thank few great individuals who had been supporting me in my academic journey and had been instrumental in completing this thesis.

I feel very privileged working with Professor Goli Rezai-Rashti, and I am grateful for her insightful guidance, relentless support, and in taking a leap of faith.

I gratefully acknowledge the eight participants who kindly took part in this study and shared their voices.

I would like to also extend most gratitude to my family for their unconditional love and support. To my mom, Shaima--thank you for the countless sacrifices you have made for my siblings and I, and enabled me to pursue my dreams with no boundaries.

Finally, I want to acknowledge Naim, who was always an endless source of inspiration to me, who had unconditionally mentored and supported me throughout this journey. 


\section{Table of Contents}

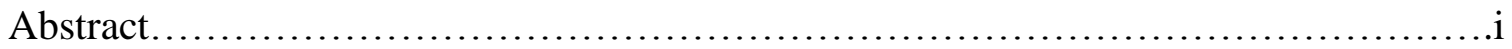

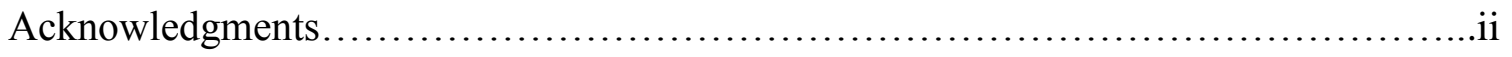

Table of Contents..........................................................

List of Tables...................................................................

List of Appendices.........................................................

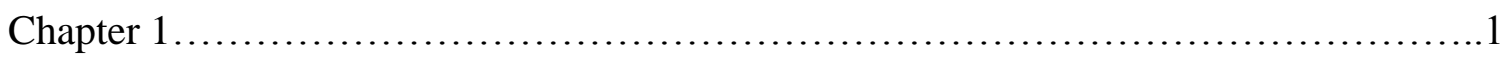

1. Introduction...........................................................

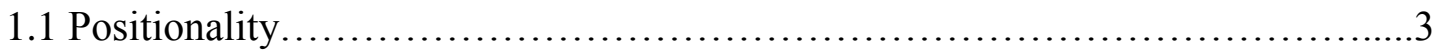

1.2 Research Questions...................................................5

1.3 Gaps in the Literature.................................................

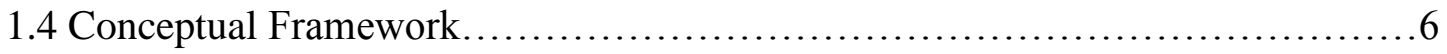

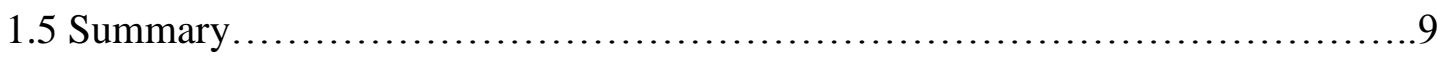

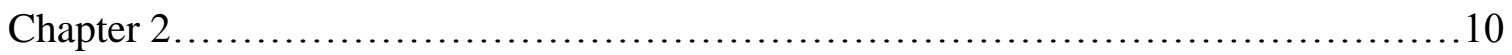

2. The Literature Review................................................. 10

2.1 Islamophobia..................................................... 10

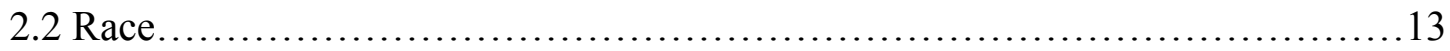

2.3 Negotiating Muslim Identity in a Post-9/11 Era.......................... 15

2.4 Shift from ethnic to religious identification............................... 19

2.5 Muslim Students and Their Educational Experiences..........................24

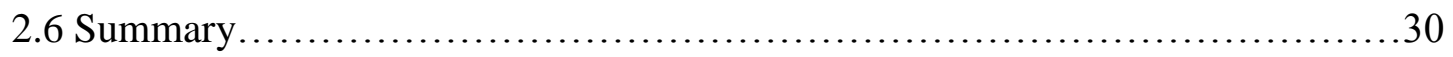

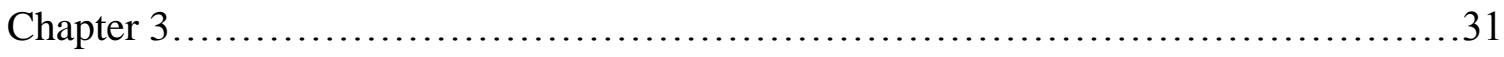

3.Methodology ........................................................... 31

3.1 Research Design \& Rationale......................................... 31 
3.2 Participant Selection..........................................................

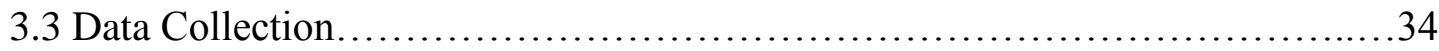

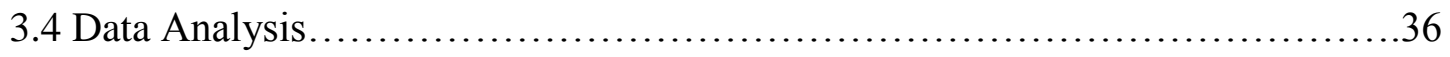

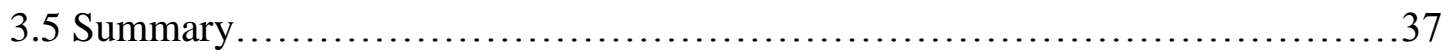

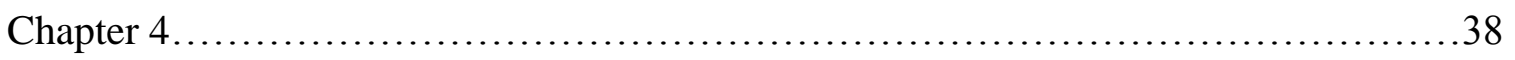

4. Findings and Data Analysis.......................................................

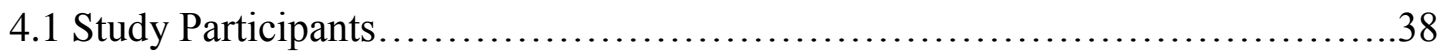

4.2 Theme 1: Islamophobia on Campus........................................40

4.3 Experiences with Faculty Members..........................................41

4.4 Interaction with Non-Muslim Students....................................53

4.5 Muslim Student Experiences with Student Service Providers....................63

4.6 Theme 2: Strong religious identity..........................................67

4.7 Resisting and challenging Islamophobic sentiments.........................8 80

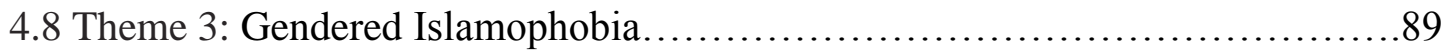

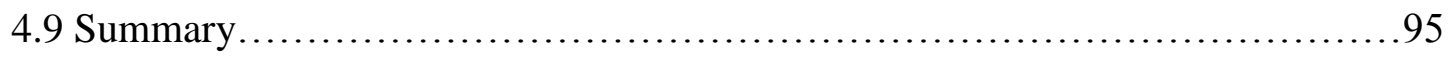

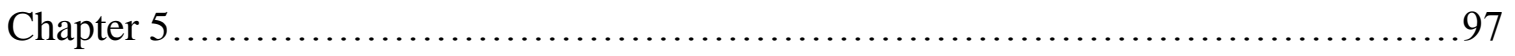

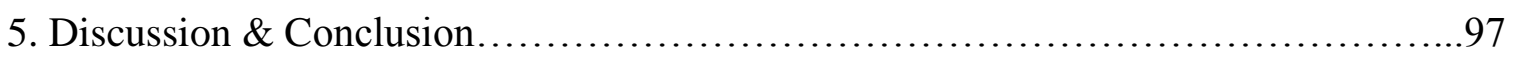

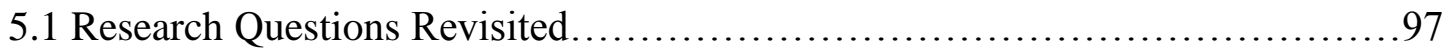

5.2 Contribution to the field................................................... 100

5.3 Limitations of the Research............................................ 100

5.4 Implications for Future Research........................................ 102

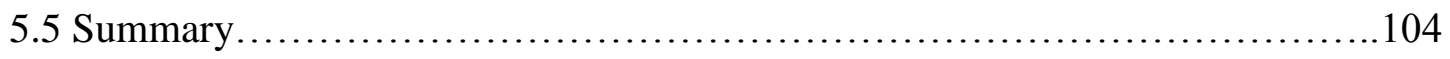

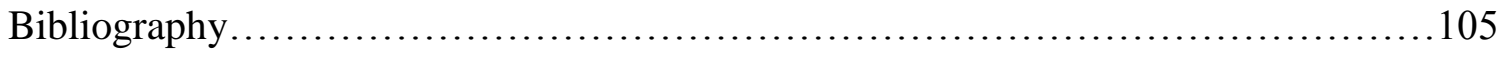


Curriculum Vitae.......................................................... 114 
List of Tables

Table 1: Research Sample...................................................39 


\section{List of Appendices}

Appendix 1: Letter of Information.............................................111

Appendix 2: Consent Form..............................................113 


\section{Chapter 1}

\section{Introduction}

Islamophobia is a complex phenomenon that is impacting the global community, especially the lives of Muslims. Since the publication of Edward Said's (1978)

Orientalism, it has been widely accepted that the West has long linked Islam with negative images, stereotypes, and violent extremist practices (Bleich, 2011). Said (1978) illustrated how Islam is Otherized as a religion and a culture that is inferior, violent and irrational. It is important to note that Islamophobia can be framed in terms of globalization, as it used as an instrument for creating hatred environment against Muslims, in this view globalization is deemed as global Westernization, identified with modernity, vs. tradition and cultural backwardness (Eisenstein, 2001). Thomas L. Friedman (2000) defines globalization as a struggle between those who desire to be modernized and those who cling to their ancient, pre-modern cultural ways. Some of the Western commentators are fixated on this Islam/modernization dichotomy (Hester, 2001). This is consistent with the Western scholarly tendency and the colonial discourse to encompass other cultures into Western culture. Islam especially evokes the most extreme resistance to this trend (Khamehi, 2015). Such a context involving the Orientalist imaginary depicts Muslims in a condescending manner has exacerbated and fed a particularly virulent form of Islamophobia.

Muslim communities in the West are directly and indirectly affected by terrorist attacks carried out in the name of Islam. The attacks on the United States (i.e. 9/11) had a significant global effect and they demonstrated how the world has become one place. The representation of Muslims living in the West is thus colored and shaped by international 
events (Larsson, 2005). The events of 9/11, 7/7 London bombings (2005), and the Paris (2015) and Brussels (2016) attacks, not to mention the invasion of Iraq (2003), Afghanistan (2001) and the broader 'war on terror', have been used to bring Muslim identity to the forefront of global media (Housee, 2012). The aftermath of these terrorist attacks has further intensified the West's scrutiny of Muslims, resulting worldwide in arsons, physical assaults, even murders. Muslims have been constantly constructed as Other; the use of the "us" versus "them" dichotomy, and the language of evil have characterized the political discourse, which has spurred intense Islamophobia (Brunet, 2013). The global nature of these conflicts has affected Muslims in Canada, even though the latter may be separated from the former in time and space. The contemporary representation of Muslims in the media is mainly framed in a monolithic way, and consequently, Islamophobic content transcends geographical spaces and boundaries. As a result, focusing on experience is paramount to understanding the damaging effects of Islamophobia on Muslims.

Anti-Muslim feelings in the West have increased, although Muslims have not only mourned for the victims of 9/11 and other terrorist events but have also voiced their opposition to the extremist ideology of Al-Qaeda and violence (Esposito \& Kalin, 2011). The unique problem for Muslims is that their faith is being increasingly defined by the actions of a small group of morally bankrupt terrorists (Brunet, 2013). This is largely due to the rhetoric of anti-Islamic groups fueled by the Western media, blurring the distinction between Islamic terrorists and mainstream Muslims. As a result, anti-mosque incidents have escalated in recent years, and hate crimes against Muslims have been on the rise. Six other anti-Muslim incidents occurred in Ontario following the Paris Attacks. 
One example involved a Muslim woman being physically attacked in a particularly violent incident outside of her children's school in Toronto: she was thrown to the ground and punched several times in the stomach and face (Mehta, 2015). Because of incidents such as this, Canadian Muslims have expressed living in a climate of fear and suspicion (Brunet, 2013). Thus, there is a need for evidence-based research dealing with antiMuslim hate crime and examining the impact of Islamophobia. In this complex environment where many Western countries are engaged in military conflicts with predominately Muslim populations, and the domestic war on terror is primarily focused on Muslims, this research is timely and much needed to understand the experiences of Muslim university students in Canada. This research will contribute to scholarly academic and general public knowledge about personal experiences of Canadian Muslims in the backdrop of increasing anti-Muslim bigotry.

\subsection{Positionality}

With respect to the researcher's positionality, it is essential to highlight aspects of my identity that are at play. I was born to a Muslim Afghani family and raised in Canada; I identify myself as an Afghan-Canadian. Motivation and interest in this subject was sparked by disturbing recent events in Western countries. I embarked on the research with some insider knowledge because of my overall experiences as an immigrant, educator and a Muslim enrolled in higher education institution. I could be perceived as an insider based on my religion, and this enabled me to understand and try to accurately represent participants' experiences. We shared some common reference points, enabling me to build a rapport and trust with my interviewees. I could also be seen as an outsider on the bases of my non-visible Muslim identity. Although I am a Muslim, I have never 
experienced overt Islamophobic discrimination in public, nor in the university context. This is due to the ability to cross social boundaries without modifying any part of my religious identity. Additionally, I have experienced racism not because of my religion, but through stereotypical conception about my ethnic background, skin colour, accent, and culture.

Due to my positionality as a Muslim, Afghani woman, I was an insider/outsider in this study. The constraints and limitations associated with 'insiderness' have been highlighted in the literature (Chaves, 2008; DeLyser, 2001; Wilkinson \& Kitzinger, 2013). Researchers bring their own experiences and history to the role of researcher and influence research processes (Brannick \& Coghlan, 2007). However, being an insider was beneficial in establishing rapport and trust with the interviewees, and it provided a level of safety and comfort for the participants. I saw such grace in the way each participant articulated and shared their experiences, and wanted to capture their awe-inspiring stories. For the most part, I saw myself reflected in their narratives. As an insider researcher and Muslim woman, I felt a tremendous amount of pressure when one of the participants kindly thanked me for conducting this pivotal research and attempted to represent accurately the voice of the participants. Furthermore, my personal experiences as an immigrant, a Muslim woman, and given the current climate, attracted me to this research topic, which thus may be deemed as a source of bias that may have influenced the interpretation of data. Notwithstanding, I do acknowledge this aspect and, as a result, I remained cognizant of how this could affect the data. 


\subsection{Research Questions}

This study investigated the experiences of Muslim students attending institutions of higher education in the context of increasing Islamophobia. The study critically explored how these Muslim students reside at the nexus of religious oppression, confronting racism and Islamophobia in society at large. I examined the experiences of Muslim students following recent terrorist-labeled events. It is important to acknowledge that racial discrimination, stigmas, and becoming 'Othered' are in a constant state of flux, affected primarily by catastrophic terrorist-labeled events both domestically and globally. It is important to emphasize that remnants of the past remain deeply embedded in and bleed through to the present and modern construction of race and religion.

Within this complexity lies the purpose of this research. I used qualitative research in the form of the case study to investigate the following questions:

(1) What are the experiences of Muslim Canadians attending institutions of higher education in the current context of Islamophobia?

(2) How is the rising anti-Muslim sentiment impacting the academic performance of Muslim students?

(3) How do Muslim students negotiate or navigate their identities subsequent to recent national and international tragic events (i.e. Paris Attacks, San Bernardino and other terrorist atrocities)?

\subsection{Gaps in the Literature}

Identifying gaps in existing research, the literature is mostly limited to the European and American context. Moreover, there is a major focus around the appropriateness of the term "Islamophobia". Very little academic material is available on 
the subject of religious discrimination. Thus, it is difficult to examine Islamophobic activities or racially motivated crimes and to identify potential contributory factors. The majority of the research is focused solely on hijabi ${ }^{1}$ Muslim females, and the focus of this thesis is to highlight the missing voices of non-hijabi girls to broaden the scope and provide insights into the experiences of various types of Muslim girls, especially those who are not currently represented in the research literature.

\subsection{Conceptual framework}

In this section, I will explain how Critical Race Theory (CRT) guides this research. The study will then move on to position the concept of Islamophobia within the broader discourse of race in an attempt to contextualize the phenomenon of Islamophobia.

This thesis presents racialization as the lens through which to understand the experiences of Muslims in the aftermath of recent terrorist-labeled events. The argument that I put forward in this proposed research is that Islamophobia is a form of racism and that religion can be raced (Garner \& Selod, 2015). Using racialization as a key analytical concept enables us to understand that Muslims are homogenized and degraded by Islamophobic discourse, regardless of physical appearance, economic situation, or country of origin. Using the religion can be raced logic identified by Fred Halliday (1999), about whether a, “... phobia can be directed toward people or a religion, is sidestepped because this distinction loses its significance" (Garner \& Selod, 2015, p. 12). In other words, physical bodies are the site of racism, even though the path toward those bodies lies through cultural terrain (Garner \& Selod, 2015). For instance, the markers of 
Islam such as the hijab, a Muslim name, or a nation of origin can be read as Muslim-ness onto individual bodies.

Islamophobia and racism are conceptualized as indistinct phenomena. At this stage, it is no longer the case that association between racism and Islamophobia remains to be made. Vakil's conclusion (2010) is unequivocal: Religion is raced, and Muslims are racialized (Garner \& Selod, 2015). This concise statement represents the starting point. The definition of racism is comprised of three elements:

1) A set of ideas [i.e. an ideology] in which the human race is divisible into distinct 'races', each with specific natural characteristics derived from culture, physical appearance or both.

2) A historical power relationship in which, over time, groups are racialized. That is, they are treated as if specific characteristics were natural and innate to each member of the group.

3) Forms of discrimination flowing from this [practice] ranging on a spectrum from denial of access to material resources at one end to genocide at the other (Garner \& Selod, 2015, p. 11).

In order to conceptualize Islamophobia as racism and get to the root of it, it is essential to approach the analysis from a CRT perspective. CRT is a theoretically grounded approach to research that foregrounds race and racism in all aspects of the research process and values experiential knowledge of (a) marginalized group(s) (Housee, 2012). CRT is a perspective that is developing, and adapting to new ideas. As a perspective it is a set of interrelated beliefs about the significance of race and racism, and how they work in Western societies (Housee, 2012). CRT has a series of defining elements and conceptual tools. First, it locates race and racism within a discourse that identifies, "racial oppression as primarily an institutional and systemic problem and racism as a structural manifestation of white social, economic and cultural power" (Modiri, 2012, p. 411). Second, it argues that racism is endemic and is deeply ingrained 
legally and culturally. Third, the theory insists on recognition of the experiential knowledge and narratives of racial/ethnic minorities via a call for context to destabilize the framework that sustains racial injustice (Housee, 2012).

CRT scholars have established the use of narrative or story telling as the main element to connecting the voice of the victims of racism with the documentation of institutional and covert racism (Housee, 2012). The CRT framework facilitates greater insight into the experiences of Muslim students because the theory values marginal voices and deems experiential knowledge as legitimate knowledge. It holds a strong stance against notions of racial essentialism. It argues that the social realities of minorities give them experiences, voices, and perspectives that are likely to be different from the dominant narrative (Housee, 2012). This is where counter-voice or testimonies become imperative:

Our testimonies are an opportunity to ponder the connections between our Individual experiences of race ...to understand how race and racism drive different interpretations of reality . . . critical race testimony is a form of pedagogical protest as it works to disrupt our understanding . . . it seeks to bear out a fuller report of racism (Housee, 2012, p.105).

Critical race theory perspective is concerned with "empowering human beings to transcend the constraints placed on them by race, class, and gender" (Creswell, 2013, p. 30). The theory offers a challenging set of insights and conceptual tools that can be used in the practice of resistance and engaging in praxis. Incorporating a theoretical framework that focuses on social inequalities and counter-narratives is essential in order to integrate "experiential knowledge drawn from shared history as the Other and form critiques of dominant social orders" (Housee, 2012, p. 104). Critical race theory is a logical framework to employ in this research because it provides a framework and understanding 
why and how racism occurs, as discussed above. Becoming cognizant of this lens enables a critical analysis and provides a framework for understanding anti-Muslim sentiment holistically, as it acknowledges the multilateral processes at play in shaping complex experiences of Muslim students.

\subsection{Summary}

In this introductory chapter, I have provided background information, research questions, gaps in the literature, and a description of the theoretical framework. Chapter 2 will focus on review of the relevant literature that shapes the foundation of this research. 


\section{Chapter 2}

\section{Literature Review}

In this chapter, I discuss a selection of relevant Canadian and international literatures that focuses on Muslim students' educational experiences in the current context of Islamaphobia. I have divided the literature into four themes. The first theme develops a nuanced analysis of Islamophobia, providing a brief genealogy of the term itself. The second theme will draw on a wealth of literature regarding race and racism, as a way to understand the conflation of race and religion. The third body of literature explores the construction of Muslim identity. I will also discuss literature, which provides insights into the educational experiences of Muslim students in a diasporic context.

\subsection{Islamophobia}

This section briefly reviews scholarly discussions of Islamophobia to illustrate the varied contemporary uses of the term. First, I propose a critical and engaging dialogue to interrogate the contested concept of Islamophobia. The term 'Islamophobia,' became widely used in public, political and scholarly circles, as well as international organizations after the report on discrimination against Muslims was published in 1997, in the U.K. by the Runnymede Trust (Borell, 2015). Islamophobia has evolved from a politically loaded concept toward analytical purposes to make it useful for socialscientific analysis. Researchers have begun using the term to locate the history, presence, intensity, causes, and consequences of Anti-Muslim sentiments (Bleich, 2011).

Islamophobia is a hotly contested term, frequently disavowed, because it has been applied to divergent phenomena (Bleich, 2011). The term Islamophobia is problematic due to its linguistic shortcomings, meaning alternative words should be used to describe 
the prejudice facing Muslims; Islamophobia is not simply about 'fear of Islam.' Words ending in phobia connote irrational fear, and mental disorders, moving further toward the individual and the psychological element. Thus, it deflects attention away from the social, the collective, and the structural or systemic problems. However, research often disregard the literal meaning of Islamophobia, and refer it to a form of prejudice (Kaya, 2015). The advocates of the term Islamophobia view it as a significant tool to label a social reality, and to highlight injustices faced by Muslims, as well as a way of drawing attention to harmful rhetoric directed at Muslims. The critics of the phenomenon of Islamophobia perceive Islamophobia as "simply a fig leaf behind which backward social practices and totalitarian political ambitions are covered up and afforded bogus exemption from legitimate criticism and challenge" (Vakil, 2010, p. 1). The backdrop of these debates, which they give expression to, is a rapid succession of moral panics that have swept over Western liberal democracies and subsequently the rest of the world. To some, these moral panics serve as an urgent wake up-call to the politics of exclusion, hatred, and scapegoating which Islamophobia defines (Vakil, 2010). For others, the growing Muslim population in Western plutocracies and the "increasing restlessness of the global Islamist wakening attest to very problems manifested in the universal values of freedom of speech, equality of the sexes and tolerance" (Vakil, 2010, p. 1).

More informed perspectives are needed as a basis for challenging the Orientalist fictions and the politics of truth-making about Islam (Martino \& Rezai-Rashti, 2008). Islamophobia has a historical component, and it influences the construction of the Muslim identity as the historical Other (Kaya, 2015). In other words, Islamophobia is a new phenomenon for an old fear. Vakil (2010) argues that 'Islamophobia' was coined 
because there was a new reality that required naming, and more crucially, so that it could be identified and acted against. Orientalist scholarship in the West contributed in this sense by freezing Islam in its medieval form to justify that Islam, modernity and democracy are incompatible entities (Rahman, 2007). With an exaggerated "specter of fundamentalism and the contemporary re-emergence and re-assertive Islam, the encounter that the West has, and continues to have, remains one of mistrust and fear, built upon relations of superiority and subjugatory control" (Geaves, et al., 2004, p. 140). It would appear that the fear factor involved in the West's encounter with Islam has been an endemic feature of the historical and contemporary psyche (Geaves, et al., 2004). Following the terrorist attacks, particularly 9/11, the hysteria about the threat posed to the security of Western countries at all levels, as the recognition that prejudice may be triggered by threats would indicate, that the emergent response has been the dependence upon the historical archetypal Muslim enemies that continue to loom in the Canadian psyche's depths (Geaves, et al., 2004, p. 140). Sardar's views corroborate the claims made above, as he suggests that Islamophobic expression is always a re-emergence rather than a new phenomenon. The historical encounter between Islam and the West continues to sit so firmly within the psyche and is the very same psyche that has historically constructed the Eurocentric concept of Otherness (Geaves, et al., 2004). History informs and provides a frame of reference for understanding Islamophobia. There is little doubt about the significance of 9/11 and that its legacy has fed the growing specter of Islamophobia; however, perceiving Islamophobia as a post-9/11 phenomenon allows the detractors to make simplistic assumptions: Stop Islamic terrorism and Islamophobia will cease also (Allen, 2010). 


\subsection{Race}

In this section I provide a brief explanation of the concept of race, as it plays a critical role in explaining Islamophobia. Islamophobia does not always target Muslims per se; sometimes it takes on the familiar pattern of racial scapegoating (Malik, 2010). Where much of the discrimination and hatred affects those who are members of groups crudely demarcated primarily by physical appearance, and similar prejudice faced by Muslims is also applied to Sikhs, and African American as Muslims (Malik, 2010). Discriminatory incidents affect a large range of communities in spite of their diversity. They occur as a result of the racial lens through which Westerners understand the world (Malik, 2010).

The concept of race is understood as fluid, contingent, socially constructed, and subject to modifications. As identity categories take on new meanings and have material consequences via "policy and resource provision, through representations in cultural space and through the organization of institutions in civil society" (Malik, 2010, p. 194). Sri Lanken theorist of race, Ambalavener Sivanandan (1989), asserted that the new xenophobia bore all the markings of old racism (Taras, 2013, p. 422). He claims it is xeno-racism in form and contextualized this concept: "Racism never stands still. It changes, shape, size, contours, purpose, function, with changes in the economy, the social structure, the system, and, above all, the challenges, the resistances, to that system” (Sivanandan, 1989, p. 85-90).

The question is, where does Islamophobia fit with racialization? Islamophobia combines all groups under the Middle Eastern racial umbrella and makes them targets of racism. In short, Islamophobia is the latest term for a "centuries-long history of American 
state policy, cultural discourses and discriminatory practices that enforce racial boundaries around Middle Eastern in West” (Malik, 2010, p. 195). The post-9/11, global racial system emerges from the history of Western conquest, empire, and imperialism. The exploitation of racialized identities, inferring to a politics of race and racism beyond the hegemonic black-and-white binary. As many scholars argue, the reification of race is integral to the formation of the modern state. The state governs and regulates and defines populations as biological and cultural racial groups through disciplining and policing. These practices are routinized to reproduce stratified social structure and inequalities. The new forms of racializing technologies and policing tactics, such as immigration policing, racial profiling, surveillance, incarceration, and deportation, exemplify the disciplining and controlling of racialized bodies and racialization process of the American empire (Rana \& Rosas, 2006). In the post-9/11 era, Islamophobia has situated Muslims as an ambiguous racial community that encompasses the Arab-Middle Eastern-Muslim, South Asians, and possibly Latinos. The War on Terror has translated into policing against a range of racialized populations, including the curtailment of civil liberties and disenfranchisement. Such is the complication of this process of racialization that has resulted in homogenizing practices of policing (Rana \& Rosas, 2006).

\subsection{Negotiating Muslim Identity in a Post-9/11 Era}

It is crucial to employ nuanced approaches to contextualize identity and belonging among Muslim students in post-secondary institutions. Studies have shown that identity conflicts (i.e. multiple and overlapping identities) are common issues among Muslim youth (Afshar, Aitken, \& Franks, 2005). In the current climate of Islamaphobia, Muslims students have voiced their concerns about feeling disrespected by students and professors, 
and their place on university campus (Mir, 2006; Rezai-Rashti, 1994; Speck, 1997; Zine, 2001).

Ethnic identity is perceived as a relational and dynamic process of change, which is affected by the interaction of history, cultures, and societies as well as contemporary circumstances (Afshar, Aitken, \& Franks, 2005). In accordance with this view, Schmidt (2002) asserts that Muslim identification varies depending on the cultural, social and political context. The implications of identity construction have no meaning except in the context of power relations and stratification. Power relations are characterized by oppression, which is based on domination and subordination. The dominant categories of identity enable the self to be constructed in a bipolar oppositional manner, with "one pole privileged and empowered, while the other pole is stigmatized and disempowered" (Sarwar \& Yasmin, 1996, p. 15). The current theories have changed the definition of identity. Identity is now viewed as unfixed, non-static, and multifaceted (Sarwar \& Yasmin, 1996). The literature on identity presents it as a category and as a process. Identity is a very complex subject. We are not just implicated by an 'ethnic' identity; our gender/class/sexual orientation also affect identity. Within postmodern discourse, the self is defined as possessing multiple subject positions and thus is embedded in different power struggles. We need to consider various markers of differentiation such as gender, race, ethnicity, sexuality, and religion and their role in constructing multiple identities for Muslim students. As Hill-Collins (2010), argues we need new categories of analysis that are "inclusive of race, class, and gender as distinctive yet interlocking structures of oppression" (p. 20). An intersectional analysis is important with aiding our understanding of the structural bases of domination and 
subordination. Butler (1999) also emphasized the impacts of intersectionality such as race, class, and gender on the choices that second generation Muslim women in Britain make in the process of cultural redefinition. Therefore, the process of cultural redefinition is not defined by individuals' preferences to choose one cultural model over another. Rather, it is the result of the ways in which people perceive and respond to factors such as race, class, and gender to transform their own identity (Butler, 1999).

However, identity for people of faith is conceptualized as a fixed concept of the self, based upon race, gender, class, and ethnicity (Rida, 2004). In this sense, the media's fixation on the narrative of Muslims lacking self-determination and agency, leaves little room to know about the complex processes of subjectivity, inter-subjectivities, and how each one of us occupies multiple spaces. This lack of social knowledge begins with ambiguity, and we must raise important questions about the need to rethink agency and an essentialist understanding of identity in relation to Muslims as entailing acts of resisting norms (St. Pierre, 2000). The danger of subsuming Muslims into a single category places different people into the category of Other; inferring their differences across other identity categories, such as class, ethnicity, and race are subsumed under the essence of a single religious identity category. In reality, Muslims are highly a diverse population. The main concern is that "differences are eased by identity, people can be more easily slotted into a hierarchy or grid and then manipulated, dismissed, and oppressed" (St. Pierre, 2000, p. 480). This is consistent with the colonial tendency to present one-dimensional image of Muslims. Thus, this study attempts to critique the limits of Orientalist construction of Muslims as primitive and violent, provide important 
knowledge that illuminates the significance of agency in the negotiations of Muslimness ${ }^{l}$ (or increased religiosity) and identity management, which defies reductive stereotypes (Said, 1979).

There are a number of studies that have explored the process by which Muslim identity is constructed. The concept of hyphenated selves has been highlighted by Shryock (2010) in his book entitled Islamophobia/Islamophilia: Beyond the politics of Enemy and Friend. Shryock argues that while there is a collapse of identities overseas, Afghans, Iraqis, and other Muslim nations are grouped in a uniform class of Muslim enemies by American civilians. On the domestic front, the majority of civilians have a similar tendency to lump their enemies sloppily at home. The inability to distinguish between Arabs and Muslims has serious consequences on the domestic level such as immigrant communities being targeted (Shryock, 2010). Nadine Naber (2006) also addresses this specific issue, as she writes: “... when the United States goes to war in the Muslim homeland, the significance of this process is that it legitimizes the distinction between Americans and a constructed enemy Other/enemy of nation" (p. 236). Rabbi Paley (2008) also provided an elaborating critique of foreign war. According to him, the "foreign war is not just a foreign war against real Muslims, who pose no threat to us, but also a war waged for the sake of our identity. The domestic struggle of various diasporic communities is one of definition: Who are we?" (Shryock, 2010, p. 70). This question has shaped the communal struggle between Arab and Muslim American communities, which is charged by distrust of the Other. Communal identities will continue to be compromised if a place is carved out for an opposing identity (Shryock, 2010). Those who are deemed

${ }^{1}$ According to English Oxford Dictionary, Muslimness is defined as the quality or fact of being Muslim. 
as Muslim are held accountable, labeled as terrorists, and are asked to apologize for attacks they did not carry out or support. The everyday American assumes that Muslims possess the most dangerous dual loyalty to Islam and their nations. This sort of politics, which is grounded in Orientalist depiction of all Muslims as stigmatized, and views them potential terrorists, deflects the attention away from examining the context of neocolonial forms of power and structural or systemic problems (Shryock, 2010).

Zine (2000) has discussed the issue of religious identity and the cultural challenges of preserving an Islamic identity amongst Muslim students. Scholars such as Khan, Barth, Zine, among others, have discussed the way religious boundaries are protected through notions of exclusion and resistance. Muslim students face multiple challenges while attempting to preserve their Islamic identities. Based on a critical ethnographic study, Zine (2000) examines how Muslim students use formalized resistance to assert a collective identity and facilitate the development of Islamic subcultures in schools. She also explores how "peer pressure and the problems of social integration experienced by Muslim students in public schools provide both an impetus and barrier for collective social organization" (p.13). Many Muslim students who participated in her study were able to negotiate their religious identities by creating Muslim spaces within their school by wearing the veil to further assert their Muslim identities. Thus, they use their identities as a tool to resist and counteract their marginality within Eurocentric schools. These studies provide important knowledge that illuminate the significance of agency in the negotiation of Muslimness which can enlighten the discourses on Islam, and open new avenues of conceptualizing what it means to be a Muslim. 
Another study of Zine's (2003) reiterates the modes of resistance to counteract marginalization. She argues that Muslim students tend to resist assimilation, and attempt to maintain religious lifestyles and "counteract their racial, ethnic and religious marginality in secular Eurocentric institutions by building sites of resistance through collective activism" (p. 54). Muslim students use the space of university to express their identity as a basis of activism to defend Islam. For instance, Muslim Student Associations (MSA), which is an active student group across University and college campuses in North America, creates sites of resistance and refuge (Zine 2000; Schmidt 2004). Yet such identity construction has implications: marginality and the lack of acceptance affect one's ability to acquire cultural capital, which is essential for social success (Mir, 2011). Mir (2011) points to the issue of assimilation and its "inhospitable and harmful nature towards cultural identities such as Muslim, ethnic, transnational, and immigrant cultures" (p. 559). Mir (2011) concludes that Muslim Americans who wish to integrate into American society should "disguise themselves, and should normalize as less religious, less cultural, and less ethnic, while those seeking to resist assimilation have the option of loud identities' (p. 559). These studies conceptualize the complexity of racialized identities. This entire process of either joining in with the social practices of mainstream or resisting the social pressures puts the Muslim students on the margins of social life and renders them outcasts.

\subsection{Shift from ethnic to religious identification}

The recent intensification of Islamophobia has produced both unity and tensions between different generations, as well as between the host society and the Muslim communities (Afshar et al., 2005). The current context of Islamophobia has intensified 
the generational division, both in terms of political and social adherence, which is not easily bridged and is becoming more pronounced. Amongst the current generation of young Muslims, Islam has become a more important identity signifier than it is for their parents (Afshar et al., 2005). In other words, ethnic identity becomes subsumed within a focus on religious identity. In 1993, 87 percent of second generations were born in the U.K. and most of the young Muslims found that they were still identified as migrants (Afshar et al., 2005). After September 11, the host society in the U.K. and the media were ascribing identities and new labels to Muslims that further distanced them from the host and connected them to their faith group. This had a very profound effect upon the Muslim youth, who reacted by defining themselves as true Muslims by embodying religious practices. In extreme cases, this included observing the activities of different brands of radical Muslim groups (Afshar et al., 2005).

A series of interviews were conducted with Muslims of Pakistani origin in West Yorkshire, as the British part of a Toronto-based international study of Muslim Diaspora. A majority of the younger participants stated that their faith has become stronger in recent years (Afshar et al., 2005). The faith that they embrace is not the traditional beliefs that their parents wish them to have. Their Islam is one that constitutes part of an imagined dynamic, unbounded world community — the Umma. ${ }^{2}$ This is a righteous, strong and united Islam, which does not deter them from maintaining their identities as British, Pakistanis, or Gujaratis, but encompasses all desired identities within "a permeable unbounded community of dreams and aspiration" (Afshar et al., 2005, p. 277). This community is "not a homeland, it is not a geographical place and there is no intention of

\footnotetext{
${ }^{2}$ Umma refers to the geographically unbounded single community of believers
} 
return” (Afshar et al., 2005, p. 277). The British Muslims have a universalistic Islamist consciousness that is not diasporic as rooted in the concept of Umma. There is "no homeland; the earthly experience is merely a path towards the eternity. It is the correct path seratol mostaqim that matters, not the earthly political or regional divides" (Afshar, Aitken, Franks, 2005, p. 277). The practices that were considered mainly religious have become the symbols of identity.

For other young Muslims, Islam is a core part of their personal and political identity, but their interpretation of Islam differs from their parents. In other words, identification has involved the reconfiguration of the meaning of 'Muslim'. Given that identities are the product of exclusion and constructed through difference in relation to the Other (Hall, 1996). This particular type of masculine identity is constructed, which is racialized and ethnicified, in opposition to the experience of oppression and dominant discourses of masculinity (Afshar et al., 2005). From the outset, the Muslims' narratives are used as a means by which to counteract a hegemonic understanding of Islam that has been shaped by persistent colonial images of Muslims (Martino \& Rezai-Rashti, 2008). Thus, the Islamic identity is presented as a political dissent and a symbol of protest. The first and second generations of British-born Muslims are increasingly becoming religiously oriented partly due to marginalization and perceived Islamophobia.

Ghaill and Haywood's (2015) research, like Afshar's (2005), also highlights the extent to which Islamophobia helps to crystalize an intense religious identity. Young Muslim men of Pakistani and Bangladeshi origins were interviewed by Ghaill and Haywood (2015) in Birmingham. The participants suggest a shift from ethnicity to religion as the primary official marker of their racial identity. The exclusion of minority 
religions from the national collectivity has created a process of racialization. People of color used to be identified with the places or origins that have historically served to mark differences, and now they have become known by their religion. The racist stereotype of the Paki has become the Muslim fundamentalist (Ghaill \& Haywood, 2015). The social lives of young Muslim men are marked by an "intensified global surveillance, cultural pathologization and social and racial exclusion that is more complex that this suggested shifting classification" (Ghaill \& Haywood, 2015, p. 101). While Muslim-ness, serves an important role in this interplay, it does not completely determine ones' identity; socioeconomic status plays a significant role, as well as local and regional identities. The interviewees concluded that they attribute a particular meaning to Muslim affiliation, and their 'double consciousness', is thus founded on the painful discrepancy between their view of themselves and other Birmingham Muslims as being unremarkably normal (Garner \& Selod, 2015). In the midst of a racialized political discourse that seeks to emphasize Muslims as a suspect community of having a "fragile engagement with Britishness, and potential allegiance to external forces brining political violence" leads to a form of displacement that involves remasculinization that is grounded in an oppositional politics (Garner \& Selod, 2015, p. 16). These studies have provided important data on the psyche of Muslim youths and illuminates how Muslims are creating a combative Islamic political identity to increase cohesion and unite Muslim communities in opposition to the rising Islamophobia in their host society. Muslims have no common language, or nationality, but Islamophobia creates a strong bond and brings all Muslims together.

\footnotetext{
${ }^{3}$ Double consciousness - means identity that is divided into several facets (Du Bois, 1903).
} 
Ramadan (2004), however, cautions about the dangers of the anti-Western identity. Ramadan argues that Muslims in the Western Diasporas do not have to create their identities against the West. Many Muslims embrace an anti-Western identity for a false sense of protection, which further alienates Muslims, and strengthens the "logic of the dominant system whose power, by contrast, lies in always being open, pluralistic, and rational" (p. 5).

Islamophobia shatters Muslims' sense of belonging to their societies. In addition, Islamophobia creates a wide gap between Muslims' perception of their identity of who they are and the way in which they are perceived by the host society. Groups on both sides of the divide demand that Muslims abandon either their faith or their national allegiance (Afshar et al., 2005). Young Muslims in the United Kingdom are experiencing these changes. Young men have difficulty in defining their identity in terms of host or kin community, either by adopting ritual emblems and practices and embracing extreme ideologies that act as boundary markers, or fully integrating into mainstream society. In West Yorkshire some young second and third generation males project:

A hard image of tough aggressive macho men... and claim membership of Hamas and Hizb-ut-Tahrir... Yet the same individual do not know what Hamas or Hizb-ut-Tahrir represent and are unaware who the Shiias are, and how they differ from Sunnis (Samad, 1998, p. 434).

On the other side of the Atlantic, even Muslims who are citizens of the U.S. can be excluded discursively from belonging to the nation. Garner and Selod (2015) reveal how Muslims are racialized through religious signifiers. South Asian- and Arab-Americans are denied cultural citizenship when they are identified as Muslim. Their religious identity is treated as if it is incompatible with their American-ness (Garner \& Selod, 2015). In this sense, Muslims are cast as refusing to assimilate into the mainstream society 
This collection of scholarship enabled us to delve into how the actions toward Muslims influence how they perceive themselves. Employing Du Bois' double consciousness concept to scrutinize Muslim identity underpins the experiences of Muslims; its basic premise is that people of color learn to read themselves through white or majority perspectives, and regulate their behaviours accordingly. What emerges from Du Bois' work is that Muslims in the West deploy a double consciousness to minimize the risks of discrimination and confrontation of Islamophobia and bigotry.

\subsection{Muslim Students and Their Educational Experiences}

Watt's (2011), study finds that Islamophobia is one of the barriers to educational success. The impact of negative of attitudes towards racialized Muslim students on their educational achievement has been examined by a number of researchers. Zine (2003) states that some teachers and guidance counselors hold negative perceptions towards Muslim students. Muslims girls who wear a hijab struggle with their teacher's common misperception.

Similarly, in a study exploring the experiences of Muslim college students, conducted by Speck (1997), cultural differences and prejudice based on religious practice were found to negatively influence Muslim students' educational experiences. Due to a perceived lack of respect from professors, Muslim students often viewed their academic integration as estranged. For instance, a Muslim woman wearing the hijab reported that some faculty members held negative misconception about veiled women. She also expressed being perceived as docile, oppressed, and as having limited English speaking ability due to her veil (Speck 1997). Discrimination is further magnified when students have a limited English proficiency or are unable to correct misconceptions or defend their 
religious practices.

Exploring the experiences of Muslim high school students, Zine (2001) and Rezai-Reshti (1994), also noted the issue of racism and discrimination. In particular, Muslim girls wearing hijabs described their interactions with teachers as being framed with negative Orientalist assumptions (Zine, 2001). For example, some teachers thought that Muslim women are oppressed at home and that Islam does not value education for women. Such notions were communicated through hidden curriculum and streaming practices, where some Muslim girls were encouraged to avoid academic subjects and follow lower non-academic streams (Zine, 2001). The veil as a signifier of "Islamist oppression against women within dominant regimes of Western knowledge raises crucial questions about the need for educators to challenge the authority of Orientalist worldviews of Islam and the Muslim subject” (Martino \& Rezai-Rashti, 2008, p. 426). These are experiences of social rejection, of being excluded simply due to their religious identity and the negative connotation associated with the veil (Zine, 2006). School, from primary grades to higher education, continues to be a "source where our sense of self must be negotiated with the master narrative. It is not a coincidence that although we are thousand kilometers apart, we all share so many experiences about being the Other in schools" (Housee 2012, p. 111). With these encounters, a specific discourse of foreignness and Otherness emerges. In general, all the participants in these studies express similar feelings. Their unwillingness to compromise their Islamic identities increases their vulnerability and renders them as potential victims of Islamophobia. Cultural and racialized identities are significant to the learning experiences of students. Exploring the role of religion in shaping the educational identities of Muslim 
students, Housee's (2010) argument is insightful, as it illuminates the experiences of the veiled women. Housee's (2010) participants raised their concerns that if Islamic practices, such as hijab wearing, were banned in public schools, Muslim students may opt to go to Muslim faith schools in order to maintain their religious practice:

I believe that the hijab should not be banned because it will separate Muslims from non-Muslims and this will not allow them to integrate. This is promoting separation and does not allow for multicultural education. Integration is good, ... because we [Muslims] should be able to be educated in a multicultural environment, where all cultures, religions, languages are respected and everyone is equal. This can reduce racism and allow a better understanding of people with different cultures and ideas. Multiculturalism should be emphasized, so there is a better understanding and respect. Students should be able to get along with people who are different to them, because this gives them the opportunity to learn about others and to understand them better, instead of just getting ideas from the media (p. 430).

In the current discourse on Islamophobia, which portrays Muslims as terrorists, it is evident that some students will associate this with other controversial topics, such as separate faith schooling. The study also noted that during the formal class discussion, a white student expressed concerns around Islamic schools promoting extremism (Housee, 2010). Another Muslim student also aired her views:

I felt that Muslims are portrayed as terrorists. White and non-Muslim students in this class put us in that category. These white students forget that we are born British, but we also like to maintain our religious identity and our nationality. The majority of the white students in the debate found the Islamic dress and veil pathetic. My view on the whole Islamic dress ban is that it puts fear into Muslims and encourages some Muslims to stop being religious (p. 431).

While the majority of Muslim students do not report incidents of verbal assault, they frequently have to explain and defend their religion to non-Muslims. It is difficult to educate or defend your religion, and it can be painful when minority rights are 
challenged. As Housee (2010) states, "You wait on a friendly supporting voice to step in and defend you. And sometimes it is a voice from another source, in this case a nonMuslim, which is needed to shift the bigotry" (Housee, 2010, p. 431).

Another intriguing study, conducted by Zine (2006), explores the experiences and narratives of Muslim schoolgirls with respect to gendered Islamophobia. As the Muslim girls exchanged their stories of their lived experience of racism and Islamophobia, it became clear that these were patterns that they had encountered as the result of having their bodies marked as Muslims through the practice of veiling. The veil positioned them as foreigners who did not belong to the Canadian social fabric and the Islamophobic attitudes they encountered cast them as illegal immigrants, a tantamount denial of their citizenry (Zine, 2006).

Housee (2012) also explored the lived experiences of Muslim students. Housee advocates for counter-voice forms to challenge the mainstream perspectives. The student voice, particularly counter voice and minority ethnic experience is central to her work on anti-racism in higher education. One student shared experiences of personal harassment:

I think things have definitely got harder for us in Britain post $7 / 7$, especially for Muslim men... the media focuses on us as kind of the 'enemy within,'... 7/7 I think has scared people, they think maybe young British Muslims could pose a real threat to national security. I certainly think there's an increase in Islamophobia since the London bombings, but I don't think this is felt in everyday interactions with people, I think it's more so in the media. Personally, I don't think radicalization among the youth is anywhere near as bad as they make out. Sure, there may be a small minority of people who have extremist views... this is just a minority. The problem is that the media tends to conflate increased religiosity among us youths as a sign of extremism but that's not the case. I experience the repercussions of $7 / 7 \ldots$ they target young Asian men more because of these anti-terror laws.... I've been stopped for no reason, and my car has been searched and even though they didn't find anything, the police were still really rude to me, swearing at me and things and I think it's cos they just assume I'm hiding something (p. 111). 
This study highlighted that some of the students' views often do not get shared in wider class discussion. Student voice is a testimony of the richness and the depth of understanding that students can bring to class and are important contributions to the work of anti-racism.

One of the most significant studies of Muslim females is Housee's (2010) study of seven Asian female Social Science Muslim students following a class seminar on religious issues at a university in the U.K. The main concerns of the research are engaged pedagogy and interactive teaching methods that enable a safe space for students to voice their views and experiences, especially dealing with controversial topics such as Islamophobia, anti-Muslim racism, and the war on terror. Although the issues are provocative, the study revealed that some students remain silent and hold back their comments. The study explored the racist representation of minorities in the British context, aftermath of 7/7 bombings in London. At the level of classroom interaction, participating should be viewed as an empowering moment for marginalized students. The challenge for educators is to break the silence that holds back the views of minority students on politically charged issues. Anti-racism work requires classroom dialogue, student critiques, and engagement. Housee (2010) acknowledges the difficulties of achieving an anti-racist education, including the refusal of some students to voice their opinion in formal class setting. The silence can signify both as a consequence of oppression and a form of resistance.

Grant and Patel (2004) provide insights regarding the structural influences on the disengagement of minority ethnic students. They argue that disengagement can be an active process, and students can be disengaged by the institutions they attend as their 
voices are disregarded (Housee, 2010). bell hooks (1989) also notes on breaking the race silence, she argues that "moving from silence into speech is for the oppressed, the colonized, the exploited, and those who stand and struggle side by side as a gesture of defiance that heals, that makes new life and new growth possible" (p. 9). In short, minority students in the current climate feel disregarded, and for this reason it is important that classroom discussions challenge Islamophobic racism.

The review of the literature informs my research, as most studies provide detailed accounts of first and second-generation experiences, as they have been informed by the evolution of identity processes and cultural generational differences. Terrorist-labeled events have brought issues of identity to the forefront among many Muslim students. Evidently, one of the research questions in this study pertains to the issue of identity formation, studies specifically Sarwar and Yasmin (1996), Zine (2000, 2003, 2006), and Mir (2011) are insightful for my research. The literature reveals that Muslim students view their faith as central to their lives, and by further disassociating from the dominant culture, they reclaim and reassert their Islamic identity. The impact of campus climate on ethnically underrepresented students is also highlighted in several studies. There is recognition in the literature that Muslim students experience various forms of Islamophobia on university campuses, and a significant number of Muslim students feel that university provisions does not meet their religious needs. The objective of my research is to understand the nature of the experiences of today's Muslim students against the backdrop of world events. Focusing on the effects of university atmosphere on the educational experiences of Muslim students as well as the issues of racism and Islamophobia is insightful for fulfilling the objectives of this research. 


\subsection{Summary}

This chapter has presented an overview of relevant literature on the experiences of Muslim students in the current state of Islamophobia. This research is intended to examine whether Islamophobic prejudice upsurges following major events. A growing number of scholars have investigated the climate of anti-Muslim feelings under the label of Islamophobia, which are interpreted with the aid of scholarly theories (Garner \& Selod, 2015). First, this chapter provided a conceptual examination of the term of Islamophobia and then analyzed how the phenomenon of Islamophobia interacts with race and racism. As Muslim communities continue to grow in Western countries, and the subsequent intensification of Islamophobia created a unique context that the issues of identity and belonging become more salient, thus it is imperative to understand more fully the intersection of identity, education, and anti-Islamic sentiments. Thus, the second part of the literature introduced a number of studies on Muslim students and the experiences of negotiating their various identities. Finally, this chapter explored Muslim university students' educational experiences. These studies flesh out the rich and complex experiences of their participants. Next, Chapter 3 reviews the methodological procedures. 


\section{Chapter 3}

\section{Methodology}

Chapter Three is a description of the methodology used to conduct this research. The chapter discusses the design of the research, participant selection, data collection, and data analysis; in addition to the rationale for applying the case study method as conceptualized by Robert Yin (2014) and Michael Quinn Patton (2002). Drawing on qualitative case study research I investigated Muslim students' experiences in the context of the current state of Islamophobia.

\subsection{Research Design \& Rationale}

As a form of qualitative research, I have deployed case study research to understand the phenomenon known as Islamophobia. Fieldwork-based studies such as case studies enabled me to discover in-depth experiences and narratives about the "complexity of inhabiting subject positions across public and private spaces" (Ghaill \& Haywood, 2015, p. 99). Qualitative approaches to research are based on holistic, interpretive, and naturalistic beliefs with careful attention to the context and complexities (Patton, 2002). My research interest fits perfectly under the broad umbrella of qualitative research. The purpose of this study was to obtain a detailed in-depth understanding of Muslim students' experiences with attention to context, and to examine the impact of Islamophobic discourses in shaping the experience of Muslim students in higher education. As Patton (2002) has emphasized, some phenomena lend themselves to qualitative methods.

The strength of qualitative research is its ability to provide a deeper analysis of the phenomenon of Islamophobia. According to Yin (2014), the advantages of qualitative 
research are the "portrayals of holistic settings and impacts is that greater attention can be given to nuance, setting, interdependencies, complexities, idiosyncrasies, and context" (p. 60). One of the main characteristics of qualitative research is that the design is emergent and must remain open and flexible to permit exploration. The design can be modified even after a researcher collects data, as the researcher encounters the participants and gains and learns from their experiences (Patton, 2002). In short, the holistic design infers that the nature of the case study may completely shift during the course of study (Yin, 2014). The initial research questions may have reflected one particular orientation, but as the case study proceeds, a different orientation may emerge (Yin, 2014).

A case study is "an empirical inquiry that investigates a contemporary phenomenon (the "case") in depth and within its real-world contexts, especially when the boundaries between phenomenon and context may not be clearly evident" (Yin, 2014, p. 16). My research is intended to explore the meaning of Islamophobia, and its relevance to students lived realities. Its emphasis illuminates the social actors' views and experiences at the micro level, "which push to reassess, discard or modify our analytical frames, to be exposed to how the social actors see the world and interpret it for a moment through their eyes, thus we are forced to see things from outside our own perspectives, to allow our gaze to be creatively disrupted" (Garner \& Selod, 2015, p. 15). In other words, qualitative interviews enable the researcher to capture the complexities of individual perceptions and experiences as it depicts real-life scenarios (Yin, 2014). Qualitative interviewing begins with the assumption that the perspective of others is meaningful, knowable, and able to be made explicit (Patton, 2002). Since 9/11, Muslim students' voices have been overlooked by the dominant group. The goal of this research was to present the perspectives of 
Muslim male and female students at the post-secondary level to challenge the narratives about Muslims which is circulating in the mainstream media.

\subsection{Participant Selection}

It was crucial that the participants provided my study with in depth informationrich cases regarding their experiences pertaining to educational attainment and other challenges in the wake of the recent dramatic events (Patton, 2002). The aim was to record the experiences of Muslim university students. Due to time frame restriction and limited resources, the study was based on interviews of eight participants. Patton (2002) has suggested that making a judgment about a minimum sample sized is "based on expected reasonable coverage of the phenomenon given the purpose of the study and stakeholder interest” (p. 246). Thus, smaller sample size provides greater depth of communication and opportunity to delve into each participant's experiences.

Purposive sampling was used to identify participants, who could share their experiences. I used this particular method to create a heterogeneous sample, so that the participants were diverse individuals, in terms of ethnicity: age, past experience and social status. I defined a set of operational criteria, whereby candidates were deemed qualified to serve as cases, and the following criteria was included: young Muslims attending university in Ontario. This does not infer that they had to be devout followers of the religion, but merely that they recognize their Muslim identity as a component of who they are. Ideally, I wanted to interview individuals of Middle Eastern and South Asians backgrounds and a mix of hijabi and non-hijabi females who vary in their adherence to Islamic tenets. I preferred to employ a maximum variation as a sampling strategy to represent diverse cases and describe multiple perspectives. Criterion sampling 
works well when all participants represent people who have experienced the phenomenon (Creswell, 2013).

I obtained ethical approval from the University of Western Ontario in January 2017. In order to identify and locate selective participants, the recruitment flyers were posted in various locations in and around the university campus, including Muslim Student's Association (MSA). The flyer indicated the specific criteria, such as being Muslim of Middle Eastern or South Asian descent. The participants had to have been affected by Islamophobia. I also offered a verbal presentation to the MSA to increase participation in addition to the circulation of posters. An email was also circulated through the researcher's network of friends and family, providing a brief description of what would be asked of each participant and the researcher's contact details. The potential participant could contact the researcher via email or phone as listed on the recruitment flyer to confirm their participation. Key informants were critical to the success of this study. Such persons provided me with insights and gave me access to other interviewees.

\subsection{Data Collection}

Data collection is a series of phases of gathering information to answer the research question. The researcher engages in locating individuals to study, conducting interviews, recording information, and storing data (Creswell, 2013).

One of the most essential sources of evidence is the interview. I used a digital recorder to gain a more accurate rendition of interviews and transcribed into written format. The length of interview was from 45 minutes to an hour depending on the extent of the individual student's responses to the interview questions (Yin, 2014). The study 
procedures were conducted at the university campus or at a mutually agreed upon location conducive to conducting an undisturbed interview. In addition, I asked interviewees about their interpretations and their insights, explanations, and meanings related to Islamophobia.

The research design was interviews within a single-case study. The evidence from single case studies is often considered more "compelling and the overall study is therefore regarded as being more robust" (Yin, 2014, p. 57). The underlying logic for the use of the case study is that it either (a) "predicts similar results or (b) predicts contrasting results but for anticipatable reasons" (Yin, 2014, p. 57).

The research proceeded with the use of an interview guide approach, combined with semi-structured standardized format. The flexibility permitted by the interview guide approach enabled me to further explore and probe questions that would elucidate and illuminate the topic. Every participant was understood as a distinctive individual with a unique perspective. The interview-guide approach permitted greater individualization, as it provided a framework within which I was able to sequence the questions and make decisions about which information to pursue in greater depth, as other topics of importance may have emerged (Patton, 2002). Another advantage of an interview guide is that it enables the interviewer to build a conversation by maintaining the interactions focused while allowing the participants' perspectives and experiences to emerge (Patten, 2002). The standardized open-ended interview requires specifying key questions while leaving other important issues to be explored at the interviewer's discretion. Both strategies offered flexibility in probing and in determining when it was appropriate to explore certain topics in greater depth, or even to pose questions about new areas of 
inquiry that were not originally anticipated (Patton, 2002, p. 347).

The heart of my research was the participant's personal narrative. The interviews may be seen as counterstories, which resist the master narratives about Islam and Muslims (Sensory \& Stonebanks, 2011). It could be argued that young-adult Muslims' narratives allow an "understanding that challenges the view of Islamophobia as a monolithic force that can be read off from the assumed responses of individuals - the Muslim-‘non-Muslim' dualism” (Ghaill \& Haywood, 2015, p. 110). According to O’Connor (1997), narrative can be a "site of a powerful macro-reflexive act, also narrative positioning showcasing personal agency and self-reflexivity are key to understand anyone's autobiographical discourse” (Housee, 2012, p. 425). In-depth interviews have proven useful for the study of experiences from members of marginalized groups, as it enables dissemination of their stories (Housee, 2012). Therefore, as Creswell (2007), has pointed out, in order to hear silenced voices and want to empower individuals to share their stories, the most viable method is qualitative research (p. 40). Therefore, above all the reasons mentioned, I conducted case-study qualitative research using interviews to collect the data.

\subsection{Data Analysis}

In case-study research, the analysis of the data involve interpretation, and the data was transcribed and reduced data into emergent themes through a processing of coding also referred to as "inductive analysis" (Creswell, 2013). Agar (1980), suggested that researchers "read the transcripts in their entirety several times. Immerse yourself in the details, trying to get a sense of the interview as a whole before breaking it into parts" (p. 103). We have to reflect on the bigger picture presented in the data and form categories, 
which represents the heart of qualitative data analysis (Creswell, 2013). As recommended by Creswell (2013), I read the transcripts in their entirety and listened to the audio recordings several times, providing me the opportunity to add comments on the interviewee's responses. I highlighted quotes in the transcript that corresponded to the major themes. In direct interpretation process, the researcher pulls the data apart and putting them back together in more meaningful ways and establishes patterns and looks for a correspondence between two or more categories (Creswell, 2013). Finally, the researcher develops naturalistic generalizations from analyzing the data (Creswell, 2013).

\subsection{Summary}

This chapter outlined the methodology utilized in this study. The rationale for using qualitative case study design was discussed, and it aids to provide meaningful account and complex experiences of the participants (Patton, 2002). In addition, the participant recruitment, data collection and analysis methods are also presented in this chapter. 


\section{Chapter 4}

\section{Findings and Data Analysis}

This chapter presents the findings from an analysis of eight qualitative semistructured interviews conducted with young Canadian Muslim students attending a postsecondary institution in Canada. This study was conducted to obtain an in-depth understanding of Muslim students' experiences in higher education and to examine the impact of the discourses of Islamophobia in shaping these experiences.

An analysis of each interview was conducted with regards to relevant literature, to search students' narratives for themes that emerged from their responses. This chapter presents major themes and related sub-themes that emerged from the students' accounts: (a) Islamophobia on Campus, (b) Strong religious identity, and Resisting and challenging Islamophobic sentiments, and (c) Gendered Islamophobia. Pseudonyms have been used for all research participants in order to protect their privacy and ensure anonymity.

\subsection{Study Participants}

In this section I provide a brief summary of the participants. The students interviewed represent a cross-section of the Muslim community, and including individuals from the following countries: Pakistan, Afghanistan, Somalia, and Sri-Lanka. The study participants ranged in age from 19 to 26 years. Six females were interviewed, along with two males from a wide range of university campuses. Most of the participants were born and raised in Canada. There was a variety of types and levels of religious ideology and practice among my research participants, yet all self-identified as Muslim. Participants were in various stages of study, from undergraduate to completing Master's degree. Seven participants were undergraduates and one participant was a graduate 
student. I made an effort in these conversations and interviews to include Muslims from a variety of ethnic backgrounds and to include both male and female. Pseudonyms have been used for all research participants in order to protect their privacy and ensure anonymity. The participants are from several universities in Ontario. The pseudonyms for the 8 participants are shown in Table 1 listed below:

Table 1: Research Sample

\begin{tabular}{|c|c|c|c|c|c|}
\hline Pseudonym & Sex & Age & \begin{tabular}{|l} 
Ethnic \\
Background
\end{tabular} & Program & $\begin{array}{l}\text { Number of Years in } \\
\text { Canada }\end{array}$ \\
\hline Adam & Male & 22 & Pakistan & $\begin{array}{l}\text { Undergrad } \\
\text { Honour } \\
\text { Specialization } \\
\text { in Economics } \\
4^{\text {th }} \text { Year }\end{array}$ & $\begin{array}{l}\text { Born in Queens, New } \\
\text { York. } \\
\text { Moved to Canada in } \\
2002\end{array}$ \\
\hline Hamza & Male & 21 & Pakistan & $\begin{array}{l}\text { Undergrad } \\
\text { Global } \\
\text { Development } \\
4^{\text {th }} \text { Year }\end{array}$ & $\begin{array}{l}\text { Moved to Canada in } \\
1999\end{array}$ \\
\hline Zainab & Female & 26 & Pakistan & $\begin{array}{l}\text { Master's in } \\
\text { Political } \\
\text { Science } \\
2^{\text {nd }} \text { year }\end{array}$ & $\begin{array}{l}\text { Moved to Canada in } \\
1998\end{array}$ \\
\hline Lina & Female & N/A & Afghanistan & $\begin{array}{l}\text { Undergrad } \\
\text { Honours } \\
\text { Double Major } \\
\text { in Economics } \\
\text { \& Middle } \\
\text { Eastern } \\
\text { Studies } \\
2^{\text {nd }} \text { Year }\end{array}$ & $\begin{array}{l}\text { Moved to Canada when } \\
\text { she was } 3 \text { years old }\end{array}$ \\
\hline
\end{tabular}




\begin{tabular}{|c|c|c|c|c|c|}
\hline Aisha & Female & 19 & Afghanistan & \begin{tabular}{|l|} 
Undergrad \\
Double Major \\
in \\
Criminology \\
\& Philosophy
\end{tabular} & $\begin{array}{l}\text { Moved here when she } \\
\text { was } 13 \text { years old }\end{array}$ \\
\hline Nadia & Female & NA & Sri-Lankan & $\begin{array}{l}\text { Undergrad } \\
\text { Environment } \\
\text { \& Business } \\
2^{\text {nd }} \text { year }\end{array}$ & Born/raised in Canada \\
\hline Maryam & Female & NA & Afghanistan & \begin{tabular}{|l|} 
Undergrad \\
Bachelor of \\
Science-Major \\
in Psychology \\
$4^{\text {th }}$ year
\end{tabular} & Moved here in 2001 \\
\hline Farida & Female & NA & Somalia & \begin{tabular}{|l|} 
Undergrad \\
Global Health
\end{tabular} & Born/raised in Canada \\
\hline
\end{tabular}

\subsection{Islamophobia on Campus}

This section focuses on the educational experiences of Muslim students at the university level. It examines how Muslim students are perceived by faculty, non-Muslim peers, and student service providers. Anti-Muslim sentiments occur in the relationship with such people, thus it shapes and further complicate their experiences in higher education. Questions of Islamophobia in universities have been all too often dismissed as a problem of the outside world, or as something that does not occur in higher institutions of learning. However, the reactions to global events such as the Paris attack (2015), Trump's travel ban (2017), and the Quebec shooting (2017) affect Muslim students. Existing research (e.g. Ali \& Bagheri 2000, Cole \& Ahmadi 2010; Feagin at el., 1996; 
Mir 2014; Rezai-Rashti, 2005; Tyrer \& Ahmad 2006; Zine 2001), and the evidence of this study reveal instances of Islamophobia and racism existing in Canadian universities, and that it may spike after major events. In light of these presuppositions, this study provided an opportunity for the participants to report any instances of Islamophobic encounters at the specific university where they were enrolled.

\subsection{Experiences with Faculty Members}

Faculty members are not exempt from displaying prejudiced and stereotypical attitudes against students from Muslim backgrounds and can subconsciously promote bias in the classroom (Greenberg \& Gotschalk, 2008; Jackson, 2010). It was evident through the data obtained from this study that Islamophobia and bias is illustrated in the relationships between professors and students. The most common form of overt bias was stereotyping, and the most common form of subtle bias was derogatory statement aimed at specific groups of students, particularly Muslim students. It can also be observable in professors who demonstrate bias themselves or do not prevent biased behavior by other students in their classrooms (Boysen \& Vogel, 2009).

Participants reported both positive and negative experiences with professors. This theme was important because it showed a contrast between encounters with faculty that were both positive and negative. Despite these challenges and the serious effects of individual prejudice, research suggests that not all Muslim students feel marginalized. Students reported that some faculty established a climate of comfort and facilitated their academic performance. As Shammas (2009) found in her study consisting of 753 Arab and Muslim students in 21 American community colleges in California and Michigan, 
with a few minor exceptions, students' comments showed almost imperviousness to perceiving discrimination on campus.

Among all the participants, Zainab found the relationship with the faculty to be the most gratifying. In the following account, Zainab described her professor as supportive, accommodating, and respectful:

I never had a negative experience in terms of wearing the niqab; in fact I had two great mentors in my undergrad. They were super-supportive, they were the ones who actually told me to pursue post-grad education. They basically said don't sell yourself short, apply to America for example, go to a better school. The professors are extremely accommodating. In fact, like last year, I had a professor who knew that Eid was coming up; she is like "oh ya I already knew that you guys had your festival coming up; you can take the day off. I'll be more than happy to oblige". So far, all the professors that I had, have been very open to my research; they have been very happy to have their office door open, and answer questions. I don't think they would be swayed by Islamophobic comments. I think generally, we have in academia, because they're academics, they can differentiate between these sort of things, I am not saying all the professors can be completely guilt free from this sort of [discrimination]...they might be thinking it, but for me the professors I had so far, especially in political science, I feel like they're more balanced in their views.

This statement clearly reflects the student's satisfaction with her professors and illustrates the importance of positive faculty relationship to Muslim students. Faculty support and encouragements appears to have the most positive and consistent effect on students' educational satisfaction (Cole, 2008). Nadia, a Somalian female student's comments were also indicative of the positive experiences with professors. As Nadia describes, her professors are respectful and mindful of marginalized people's concerns. She continued:

For example, for business class, we have to wear full-on business suit. Then I went to the professor; I was like eh I don't really feel comfortable throwing on a tight pair of business clothes, like a tight skirt. I'm not going to wear that; I don't feel comfortable. She is like: "Nadia don't worry about it", and this is after they get to know me [properly]; like I have been to your class, I have been listening, I have been like a good student. [She said] then, "don't worry about it, wear whatever you feel is comfortable". [I said] "Sir, I'm gonna wear nice blazer, I am gonna wear my 
heels, I am ganna make sure I still look professional per se". I am just the type of person that they just [say] "don't worry about it like you do you, and obviously I respect your religion and just come as business looking as you can”. They're very understanding.

It is important to note that a lot of work is being done behind the scenes by Nadia to request religious accommodation. Muslim students have distinct needs, yet the presence and unique needs of Muslim students on university campuses have received relatively little attention in literature on higher education (Cole \& Ahmadi, 2003). Nadia points out that she needs to reach out and make contact with each professor to ensure they had a face to put with her name. Building a relationship with professors is the key to receiving accommodation. The assumption is that once a professor learns that Nadia is invested in his or her course, they will be more understanding. She explains:

I sort of caught this. I think people need to get to know me, and then they will be understanding. I don't know if they would be understanding on the first day, let's say. I don't know what they're thinking of me when I sit in their class, but overtime once they see "oh Nadia sits at the front of the row, she takes notes, and she helps people, she raises her hand and she participates, she comes to my office hours", then you get to know me, and I definitely make a huge attempt to make sure that I'm good, like I have good vibes with everyone. I definitely am very cautious at school sometimes; you know like other kids don't need to go the office hours because they're fine, and they blend, but for me I need to go and make sure the professor knows me and that I do have some circumstances where I need to ask; for example, Eid usually falls on school day so I definitely make sure my professors know me.

I asked her in the follow-up question for clarification, whether building a relationship with her professors, is a burden. She said:

It is definitely, like when I say I make an effort I swear to God that I am literally looking for their door number, and everyone is like why do you have to do that? I'm like "here's the thing, I feel like I have to do that just because... again you look different, so I make sure to get the person to know me; I make sure to build that 
reputation and build that relationship with people because, I feel like I use the word "clutch" a lot, I feel like when I need them they will become clutch.... worst case scenario, what if I'm in a lecture and I'd never went to my professor, I'd always sit at the back, he doesn't know me, and what If I need to pray Salah, or what if I need to take a day off because it's Ramadan or something and that he doesn't know me? He is going to say no, even I would be like.... he doesn't know me, why would he let me do that, he doesn't know what I stand for, he doesn't know my religion, he doesn't know if I'm a good student or If I am not a good student; so I definitely make an effort to make sure that the professors here especially knows me, like I don't want to say I come with a burden or I come with crap to carry on, but yeah sometimes I need to leave the class early to pray, I need to take a day off for any reason. To be honest, I haven't really taken any days off, only on Eid. But I feel like I need to make the relationship, but with other people you don't need to sometimes, especially like my white friends, no, they don't do that crap and they still do fine, but I need to make sure I do that.

Not all encounters with professors were positive. It could be argued that Nadia had a positive experience of working and connecting with her professors. However, this is partially due to a very strong personality and fiery passion for education, and also resists the process of 'Othering' that other participants experience in the university environment. This was in contrast to the experience of Farida, who felt isolated/marginalized by her professors. Through Muslim students' narratives, I call attention to the marginalizing processes in campus social space that constrains Muslims' identities and turns it into ‘baggage’ (Mir, 2014). The barriers facing Muslim students are numerous: marginal identities on campus come with baggage, which in turn creates a multitude of struggles within the educational process. Farida swiftly recognized that she has three bags on her shoulder, "number one I am Muslim, [and] I wear the hijab; it is clear I am a Muslim, you could tell I am Muslim. Number three, I'm a person of colour like I'm not.... you know what I mean, like I have dark brown skin, like I'm a person of colour, and I'm like the whole package you know what I mean, I look very different”. 
This section presents negative comments about professors that participants found to be difficult to work within the classes. The comments ranged from descriptions of professors who ignored Muslim students to perceptions that students were treated differently than other students. In response to the questions pertaining to their experiences of discrimination and Islamophobia based on their religious identities from faculty members, some of the participants expressed satisfaction with their professors, while the majority reported that their professors held personal bias and displayed differential treatment. Research carried out by Bird (1996) on black students' experiences of higher education found that a great degree of isolation is expressed by ethnic minority students taught in a predominately white institution. In such circumstances, students often reported experiences of discriminatory attitudes and behavior from the university staff.

The practice of negative evaluation and differential treatment has been noted in the educational experiences of racial and religious minority students. Soft bigotry of low expectations of ethnic religious minoritized students can lead to negative evaluation and bias in assessment (Gibson, 1988, Parker-Jenkins, 1991; Dei, 1997). These low expectations are perpetuated by negative racialized stereotypes and Orientalist assumptions about Islam and can be construed from Muslim students' overall experiences within higher education institutions (Zine, 2001). Students of colour are likely to receive mediocre grades. Differential grading practices constitute subtle Islamophobia and racism in that they seek to attach to Muslim students the label of weak achievement or failure (Feagin et al., 1996). Hamza, a Pakistani male student presented an experience where the professor was perceived as treating Muslim students differently by producing biased results, despite similar displaying academic performance as his white counterparts: 
I've had professors who do have an issue, maybe issue with me personally, like I don't know if it's religious because of my religion or ethnicity... I don't know; that is kind of hard for me to claim, but I've had times when I felt it was the case and in those times I really wished that we would have had like anonymous grading for example where [we would be] marked by a student number; we are marked instead of our names because I do feel like maybe in some cases that does play a role in things. I think it happened more than once and ... it is just that I can't prove it, 'cause I'm also not somebody who blames my professor anything when I get bad grades. I have done same work as other people and even for example in a group assignment I've ended up with the lower mark in situations...once again I can't prove it but it just feels like that has been the case, and it has happened more than once. I would say 2 or 3 classes in my time here.

The critical element in this student's account is not the lower grade itself. The comparison with his classmates' graded work led him to the conclusion that the criteria applied to his Caucasian counterparts were not equally applied to him. Fair grading criteria are essential for all students, regardless of their background, especially for Muslim students who are the subjects of societal unfairness (Feagin et al., 1996).

Professors are not immune from internalizing and acting on ingrained biases about Muslim students. Race and religion can dramatically influence a professor's evaluation of her student. In this case, it is evident that stereotype threat can have an adverse effect on academic performance, where individuals could not counteract the discrepancy. Negative and biased attitudes that are ascribed to racialized and religious forms of identification can be constructed into modes of differential treatment that can inform the educational experiences of students. Carter et al (1999) conducted qualitative research with a small number of ethnic minority graduate students and found that ethnic minority graduate students felt stereotyped by white academics and that they did not fit into the dominant academic culture. Another example of soft bigotry of low expectations based on racial stereotypes, was presented by an Afghani undergraduate female, Maryam. She states: 
When you go out and you tell the professors where you are from and background identifies where you're from; it creates a certain stigma of you being perhaps not good enough or you have some issues or you have a lot of negative environment around you, and so you have to find yourself trying to put on this face like I am a lot more motivated, I am very determined to do this, whereas I have noticed other students that are non-Muslims or don't look anything like from that side of the world, [are] very chilled; they just approach the professors that "I want to go to grad school" something, they're a lot easier. They do tell them very naturally what to do or not to do in a very normal conversation. When you see, when I go to [the] professor or when I go to counseling advice, they do have this complete closed body language.

This statement shows differential treatment that appears to favour Caucasian students.

Professors seem sincere in trying to help white students, and they are favoured as advisees, while the marginalized students had a difficult time finding professors to advise, encourage, or affirm their abilities. The majority of the participants communicated negative perceptions of academic support provided by the faculty members. The evidence of systematic racial/religious bias in professor's expectations revealed in this study is troubling and disconcerting.

Students experience subtle discrimination and Islamophobia in their courses as well. The issue of misrepresenting Muslim students in the classroom and lack of respect for Islam are interwoven throughout the narratives of the students interviewed in this study. An instructor's misconceptions and stereotypes about Islam and the Arab world can create moments of conflict, wherein Muslim students attempt and struggle to find the balance between fitting in and challenging the misconceptions of professors and/or other non-Muslim students (Speck, 1997). This is indicated by the findings of Bruce's study (1996); the results of a questionnaire completed by 46 undergraduate and graduate Muslim students, suggest that professors may not be knowledgeable about religions outside of the Judeo-Christian religions. Thus, in their approach to teaching Muslim 
students, professors may not take into account the cultural and religious issues that are important and sensitive to those particular students. Because professors may not be knowledgeable and sensitive to other cultures and religions, they may inadvertently express bias in the classroom, and abuse their academic freedom, for instance by promoting anti-Muslim sentiment.

Professors in academia often pride themselves on being open-minded, but some evidence suggests otherwise. When supposedly informed academics perpetuate stereotypes, many students internalize the biases as the truth (Harwood et al., 2015). Clearly, these students need to negotiate the tension-ridden spaces of classrooms, and being conscious of the power relationships, find it difficult to approach professors for assistance with class content and other resources, thus limiting their ability to develop human capital (Hardwood et al., 2015). In a context of racial bias, stereotyping and discrimination and Islamophobia thrive and limit the opportunities and possibilities for racial minority students.

Assumptions about Islam and Muslims also crept into the teaching contexts in some specific cases, where issues around the relationship between Islam and 'the West' were encountered (Bagguley \& Hussain, 2007). In one case, the Muslim students in the lecture felt uncomfortable about the way the topic of Islam was treated by the lecturer. But in a more detailed account, Lina shared her concerns of a lecturer putting his biased personal views across when he should have been objective:

I have certain professors especially when I am learning about Middle Eastern studies and things like that. I have certain professors who are going to say things that aren't really true. Like they have a personal bias, whether where they're from or what religion they follow. It is always interesting to see that because that usually limits you as a student because it puts you into a space where [you would think] 
okay so that's what my professor follows, what do I follow, and it puts you in an awkward position too. I have a professor saying like the six pillars of Islam is jihad or certain things like that, or even like the Palestinian-Israeli conflict, they will put their biases in there and it puts you in a different position.

Muslims students often become objects of attention when religious issues arise in lecture, where the students are placed in awkward or painful positions. It is evident that Lina profoundly disagrees with her professor's statements, and this creates a negative learning environment. Faculty members are certainly entitled to exercise freedom in discussing subjects, but they also have the responsibility to exercise critical self-discipline and sensitivity in conveying knowledge, as it may offend certain groups of students. Another student, Hamza raised a similar concern pertaining to religious bias in the classroom, where the professor expressed his personal bias based on presuppositions of Islam:

I did have another class in which the professor was saying kind of very weird stuff; they were talking about feminism and he goes "oh in other parts of the world, there is some places that they stone women for this or that", and he had like this, very like.... kind of dangerous viewpoints in that sense, the way he was saying things out of ignorance and not understanding any context. And this is an English class, literature class, and he was saying this kind of stuff, in that kind a of setting. I think it is more difficult for somebody to have an opposing viewpoint. In the class like that, for example, I'm having argument with another student, and if the teacher decides to come to this other student's aid in the argument or defend them, that makes it more difficult to argue and to say your viewpoint because I knew because you kind of feel like you are being silenced by someone of authority.

The majority of the participants provided examples of offensive lecture content, specifically instructors' inaccurate statements, outdated terminology, and other types of offensive comments. However, as stated above, students find it difficult to correct misperceptions and often feel frustrated at their inability to participate in resolving conflicts as they feel that they are silenced, in part because, as Hamza said, the professor is an authority figure. Speck (1996) argued that since Muslim students view professors as 
authority figures, they feel hesitant to correct them. In some cases, when marginalized students corrected or challenged a comment made by the professor in the classroom, their challenges prompted another racist comment (Hardwood et al., 2015). Muslim students report demeaning contacts with the faculty, noting the problematic behaviours they encounter are deliberately Islamophobic and racist. Professors often silence students of colour, by responding to them that they are overreacting, defensive, or angry. These comments further invalidated the students of colour in front of the entire classroom. This was echoed in Farida's response:

I feel like within school, for example, I've definitely faced like you know the whole stereotypical mindset of oh she [is] the angry black woman who speaks on behalf of like something that they might incorrectly say right, so something about Somalia. Recently like they try to speak on behalf of female genital mutilation being Islamic practice in Somalia... um no, no it's not; every time I speak about it, it is like "Farida let other people talk or let other people express themselves".

The consensus of the interviewees was that most professors do not adequately understand the variety of practice in Islam. As Farida noted, most of the information was not based on facts but what the instructor believed to be true, containing misleading information about Islam. Farida added:

We will talk about like [about] global health issues, or different global situation and recently Somalia came up and female genital mutilation being a Muslim practice. And for them to make a comment like that, I won't stay silenced because stuff like that really needs to be restated; you need to be able to speak and clear things up. But it's always every time: I want to say something about it, since no one else is speaking up. It's like: "Farida let people talk, let other people say something", as if like my words are going to be like not as.... not as the best — kind of discouraging me educationally, which hurts. And I like called them out, I would speak to them personally, like: "you know what, like if you gonna be speaking on behalf of Islam then you make sure that you have your facts straight, like you can't do that". They're like "yeah I know but it's good to get other people's opinions too", I'm like 
"yeah, you could get other people's opinions, I am very open to other people's opinion. But it's like me telling you right now Christianity believes in killing Muslims, would you accept that?"

As noted, Farida responded to these stances by "calling them out". However, the professor did not provide the platform for her to express her concerns and quickly shut her down. Even after she had raised these concerns to the instructor, the lecture content and Farida's unbiased beliefs remained unchanged. The professor's refusal to change the lecture content invalidated the student's concern. This particular university had an international reputation of diversity, which added to Farida's surprise about the general stereotypes she encountered from lecturers. This isolation voiced by Farida has also been echoed in the Canadian context by participants in research at the secondary school level in Saskatchewan (Ruby, 2006). Wearing the hijab for one student led her teachers to completely disengage with her and ignore her in the class.

Muslim students are typically a minority in classrooms. As Nadia states, "I'm always in rooms like [with] a lot of white people. I literally might be one of the only person of colour", thus they always face the awesome weight of being a spokesperson for their entire group (Nasir \& Al-Amin, 2006). Representing an entire religion and feeling responsible for disconfirming stereotypes can be a daunting task for students in the classroom (Ali \& Bagheri, 2009). The interviewees clearly felt the need to promote a better understanding of Islam, in part to correct misconceptions that have led to prejudicial views of Islam. Farida elated an incident in which she did approach the professor to clarify a point the professor had made about Islam. A number of Muslim participants felt that they were constantly correcting myths about Islam. Similarly, Gregory (2014) studied the adaptation strategies amongst a group of Muslim female 
international college students. He reported that the participants actively challenged the prevailing negative stereotypes about Muslim communities.

Students of colour mentioned that they are often called on to be the spokesperson for all Muslims or perform their religion. Both classmates and instructors either directly ask students of colour to 'give the racial or ethnic/religious group perspective', or they stare, consciously or unconsciously, while students of colour are put in pressure to speak and provide a particular perspective. For example, an instructor indirectly asked Zainab to give a Muslim perspective on particular topic. Muslim students often become objects of attention when topics regarding Islam and Muslim are being discussed in the class. Zainab, a visibly Muslim student shared that following the Paris attacks and Quebec shooting attributed to Muslims and Islam there was an expectation for her to speak up in class and denounce the attacks. The participant expressed feeling pressured to speak when Islam or race were brought up in class. She recalled:

Sometimes when there is a discussion about Islam, it's like people start to look towards you to answer all the questions; because you're visibly Muslim you should be saying something. There is this sort of awkwardness, yes you do feel it. Last week, I have walked into the class, I was a little late, so they were talking about Quebec shooting, saying something like "yes they will not charge him with terrorism", and my professor looks over [at] me. I had just walked in, the class was about to start, and I'm like "I don't' know what to say". I walked in the middle of the conversation, so I didn't even know what they were sort of ending on. That was the kind of like... it was sort of awkward, people also expect you to say something. I guess they are assuming you must be super passionate about it and of course if you are; it would make sense to talk about it if you had like not walked into end of the class.

Caucasian professors have been observed to create social situations where Muslim students are placed in awkward positions. Zainab expressed discomfort about being in spaces where she was the sole visibly Muslim student. The automatic connection made 
between her and the perpetrator was deemed immediate along with an expectation that she would have something to say. In the classroom, students frequently reported being treated as representatives of their religion. When debates about Islam or terrorist attacks cropped up in class, in this case the Quebec shooting, Zainab saw heads turn toward her and demanding answers. Social situations of this kind deserve a closer examination due to damaging effects they may have. In this case, Zainab was cornered into the hard work of Muslim advocacy, trapped by her hijab in an assertive, politicized identity (Mir, 2014). Due to her high visibility in classes, as the only hijabi on the issue of Islam, Zainab was in the hot seat, the designated Muslim spokesperson who had to consistently voice and defend the Muslim standpoint. If only she were not hijabi, Zainab, wished, so she could escape the responsibility of defending Islam. Hijab puts Muslim women in the default position of representatives, and it also turns them into questionable representatives (Mir 2014). Being the unwanted center of attention is uncomfortable and serves to remind the Muslim students of the position that they are often assigned in predominately white institutions.

\subsection{Interaction with Non-Muslim Students}

A number of past studies have explored Muslim students and their interaction with non-Muslim students (Ali \& Bagheri, 2009; Cole \& Ahmadi, 2003; Nasir \& AlAmin, 2006; Mir, 2006; Zaal, 2012). Participants provided a number of examples of antiMuslim sentiments and discrimination associated with their campus experience, including being called a terrorist, victims of patriarchal norms, and singled out in the middle of classroom discussions. 
The majority of the participants in this study reported being perceived differentially by the non-Muslim students based on negative reductive image of Islam. Amongst different stereotypes identified and discussed by the participants, there are: Muslim women as oppressed and not intelligent and honour killing as justified in Islam. This finding is consistent with the findings of Zaal's research (2012). He studied Muslim students on campuses across the United States, and students related the experience of being called names, or were told to go back to their country of origin. This was echoed in Maryam's response:

Your non Muslim friends or acquaintances are just like "oh okay", so they're kind of confused as to where they should stand or what you practice, so I guess that's what I see all the time, or they have certain misconceptions.... like "Does your religion teach you to stone women or are honour killings justified?" It's difficult for you to explain that their perception come[s] from the media or from certain sources. They read like Ayaan Hirsi $\mathrm{Ali}_{2}$ and they assume that everything that person says is true about the religion, and don't take into consideration my personal experience or the personal experience of other Muslims.

The anti-Muslim sentiments stem from prejudiced attitudes, stereotypes, and lack of information about 'non-native' people. Lack of information about people from different religions is highlighted by several studies (Cole \& Ahmadi, 2010; Hussain \& Bagguley, 2007; Mir, 2014; Speck, 1996; Tyrer \& Ahmad, 2006; Zine, 2001). The comments above illuminate how some Canadians can be swayed into an Islamophobic mindset through the influence of the media. Similarly, Nadia highlighted her experiences with her classmates, mentioning the static and essentialized construction of Muslim women as the oppressed Other, timid, and voiceless. The fact that Nadia is very assertive and vocalized her opinion, surprised her classmates. She explained: 
They're usually like.... lost for words because I'm not afraid to not speak my mind. People expect us to stay quiet, stay silent, and especially being black and Muslim, they probably assume that I'm oppressed or, like since we are quote unquote run by misogynistic men, we are entitled...we are silenced and that's not even the case. I think if anything, they're like "whoa, Okay there".

Aisha reported similar experience. She encountered anti-Muslim bigotry in the classroom. She stated:

The only time, where I think that it does conflict, is sometimes when I give an opinion in class and I see the backlash even [though] they don't say something, I can feel the tension. I have been accused once by this guy when I was debating; we were in the tutorials and we're just talking about religious philosophy. It's sort of like a philosophical discussion. I give an opinion and this guy said that "you only give that opinion because you're a Muslim, and because you can't think outside of that". I felt very shocked and the TA was like "oh my God no, no, no, no" like divert, divert, divert, and said "let's listen to someone else". He didn't give me a chance to respond because it takes a lot of that to take something like that in, and then I was like "did he just say that to me?"

It is clear that Aisha was disturbed by bigoted remarks received from classmates. Prior to this, she never heard such comments. Aisha reported that after the terrorist strikes such as the Paris attacks and San Bernardino, anti-Muslim sentiments had become progressively worse. The other student felt entitled to ridicule her because she had preconceived notions of Islam and harbored overt Islamophobia. Muslim students have to engage in academic environments that condone stereotyping and anti-Islamic sentiments. Zaal (2012) added that professors must have discussions with students about war, conflicts, discrimination, and oppression so that non-Muslim students are more knowledgeable and exposed about other cultures and religions.

Some similar reports of low expectations and exclusion that were attributed to the faculty were also observed in relationships with Caucasian peers in class. A number of the participants reported their experiences of exclusion in their interaction with white 
students. Low expectations and feeling of exclusion, make them feel like they have to outshine their peers in the classroom to disprove the notion that they are academically inferior. Isolationist attitudes amongst Muslim students, who have experienced racial and religious prejudices from their classmates, coincided with findings from Zine's research (2001), positing that low expectations are informed by stereotype-based expectations, and negative assumptions about Islam are implied in Muslim students' overall experiences. Nadia referred to her experiences with her classmates who had questioned her intellectual abilities, and she had to convince her peers that she was competent:

In Business Administration [BBA], I swear to God there were three Muslim people; [but not identifiable as Muslims]. I definitely stood out and there were obstacles, like people just [say things] like "oh we don't want to be in your group", and they wouldn't say that but body language says a lot. This is sort of like awkward and weird and annoying. In first year of business you do something called pitch...I remember with many new venture group, like "okay Harris is gonna win, don't worry, girl you got this", and I was like "but I really like presenting, maybe I have a chance," and they were like "no Nadia, like, we don't know", but that you [have] never seen me present, how are [you] just automatically assuming I wouldn't do well and they're my group so you would think your group would back you up. Anyways I worked my ass off and I made sure that I memorized that; I made sure that I got other older BBA students to look at it, I went to the extra help sessions, just to make sure I perfected my pitch, so in the final day I pitched, I had no support, no one was sort of encouraging me, my own group turned their backs on me. So I'm like "whatever I'm still gonna do this for myself". So, I did my pitch, and I swear to God I killed it! I got the second highest mark in the class and my team was so shocked, and then after that it's funny; they treat you so much better. That's why I make the effort to make sure... first impressions are so important. So yeah after that, like yeah, Harris and Ryan, they're all like "oh Nadia let's be a group, let's hang out, let's study". I'm like "yea in the second first day of school; you guys didn't look at my face". I definitely have to make sure that I made a reputation of myself, and then I gained their trust and now we're all good. I mean it sucked, like you have no support.

Racial and religious bias is manifested through microaggressions. This occurred when students were asked to form a team for a class project. Although it was usually not explicit, racial and religious exclusion appears to affect group formation. The findings 
from this research were in agreement with Hardwood et al. (2015): African American and Latino students struggled to be invited into a group or to find partners because of the perceptive impacts of negative racial stereotypes about intelligence and work ethic. Another area where racial microaggressions occur is the way group work is divided. Students of colour believed that race was taken as an indicator of intelligence, thus they were assigned easier tasks. In this case, Nadia perceived that her contribution to the group project was minimized and struggled to be treated as a legitimate member of the group. Thus, Muslim students are also marginalized in the classroom environment. However they have thrived academically despite of multiple encounters with stereotyping. These examples illustrate the challenges marginalized students face in addition to the work assigned for the group to complete. On the other hand, this type of treatment motivates Muslim students to develop strategies to deal with challenges, and vehemently assert themselves to be heard. Likewise, Nadia has taken a more active role and strived to excel in the classroom and disprove the stereotype of intellectual inferiority. Resilience is an integral quality of being a successful student and the overall sense of fulfillment in the university experience.

Similarly, it was evident in Farida's interview that she experienced similar challenges as Nadia over the assumption of Muslims being intellectually inferior. Farida explained how she used student services to get involved on campus. She commented about speaking with a student leadership coordinator:

There were many times [that] I reached out to my department, team leaders of student representation of my program, and actually every time, like, I'd approached them about "can I help you guys? Can I volunteer, like, I am very passionate", no one answers. It's like "ummm you can wait a little bit", and I feel like sometimes, like at the back of my head, just like anyone else, like "if I wasn't wearing hijab 
right now, or if I wasn't black or anything like that, would you take me more seriously?" but it really does hurt you when you are so passionate about it, and you have the qualifications, that you are always told no. Basically in the global health department, so anytime I reach out to them, it's very like, "yeah we have enough people" and it's not even diverse.

Later on in the interview, she reiterate this point again:

Just like in classes or student organizing where they feel like you're simply just not qualified without hearing you out, or just kind of assuming that you are like the others, you know, like, not able to. I've applied to almost every position there was for, like, the hospitals or tutoring for kids, and I never heard back from even one, and my friend recently came up to me [saying], "oh my God, I am volunteering. I feel so overwhelmed because I don't know what to choose". We literally have been best friends since I was like seven years old and until today; like, we've done everything, like, alike. We went to nursing together and left nursing together and came to Global health together; like, there was nothing really different about us other than the fact that she is white.

As illustrated above, the negative impacts of such discrimination are substantial on the participant's educational experiences.

Universities are central hubs for debates concerning religion. In classes that discuss social, cultural, and religious topics, the potential for discrimination and Islamophobia is always present. Many of the political science and philosophy classes are focused exclusively on such topics, and the current climate makes discussions in the classroom a difficult experience for Muslim students. The simple fact of being a minority in the classroom can create an uncomfortable learning environment (Ali \& Bagheri, 2009). Maryam talked about this experience as feeling like an alien. She continues:

Some of the conversations that happen in class and it gets thrown like the name of Trump or Stephen Harper, or ISIS whatever, of course we agree with the black-andwhite image of things, but sometimes you feel like an alien; you feel like you're the new Jews of the time, it's not exactly as extreme [as] at that point, you see the underlying feeling of alienation.

To further elaborate, she continued: 
Islamophobia is, like, the new trend. Islamophobia has become a new conversation; that way, it has a lot of power in it. Because it's a trend, everyone is talking about it, you feel like your identity is now people's problem. People feel like they have a right to say something about you, even though they know nothing about you. It is, like, a pop culture.... everyone is discussing, everyone has an opinion, giving everyone [the right] to have an opinion about you.

Students have reported hostility from fellow classmates following high-profile terrorist attacks, since attacks in Paris and other attacks carried out in the name of Islam have spurred escalating rhetoric from Donald Trump. This demonstrates very vividly that educational institutions are not insulated from larger events that may provoke racist and Islamophobic incidents. This situation can become particularly difficult for Muslim students when instructors do not properly manage classroom discussions, failing to intervene when students' comments are misguided or disrespectful. Aisha described an active bigot in the classroom aftermath of the Paris Attacks:

The first time I experienced overt Islamophobia, [was] when we were talking about philosophical experiences of stereotypes in moral philosophy class. The professor asked "tell me an example of a time when a stereotype is true, first it was a stereotype that is good and then stereotype that is bad that is true". And she asked a student, maybe that wasn't [the] best idea because somebody put up their hand and they're like "oh a stereotype that is true",... and this is after the Paris Attack... he's like "Muslims support terrorist[s], that's the stereotype that's true". And I am like "did [that] just happen?" I was so shocked, like this is the University of X, it is supposed to be one of the best universities in Canada, and someone said that in the class. Again, the professor said "let's just assume that they don't", and that's what she said. But she said, "let's just assume that it's not true".

This particular university had an international reputation of diversity, which added to Aisha's surprise about the general stereotypes she encountered from classmates.

In the wake of terrorist attacks, one challenge that Muslim students mentioned, is the feeling of being called upon to defend and explain their faith. There is a constant pressure 
of demanding a response and apology from all who share their religion. This finding is consistent with the findings of several studies. Muslim students interviewed by Horwedel (2006) and Nasir and Al-Amin (2006) reported that they frequently have to explain and defend their religious values to non-Muslims. Being a Muslim on the campus of an American college, constantly requires students to serve and act as ambassadors of Islam, occasionally make choices between fitting in and confronting ignorance and reconciling Islamic values with the campus's predominant culture (Stubbs \& Sallee, 2013). Mostafa's (2006) research on the graduate school experiences of five Arab Muslims at the University of Alberta suggests that the openness of peers enables Muslim students to clarify misconceptions that exist about Muslims in the 'West'. This in turn has helped to strengthen their relations both academically and socially with their peers. Given the current climate of rising Islamophobia, the pressure of constantly defending Islam as a peaceful religion and denouncing terrorism increases; several participants in this study discussed debunking stereotypes about Islam in the classroom. Adam reflected on this:

I took a multiculturalism class last year, I remember there was one student, who was sort of, like, I don't think he was fully aware of the context of Muslim women...so he would sort of regurgitate the "Muslim women are oppressed" kind of narrative. I remember, I raised my hand, and we had a big discussion about this, but at the end you're doing it respectfully, and even if you're changing one mind, that's better than not saying anything or not speaking in the class at all.

Adam and Zainab encountered similar experience. Zainab also pointed out:

I took few Political Science classes and they would occasionally discuss Muslim issues. And sometimes it would become bad, so like some kid said, like, the "savage barbarian Palestinians", and then I called him out on it. There's like a refugee issue, and a lot of people talked bad about the refugees. He said, like, "I blame the Palestinian, savage, Palestinian culture for their problems". So, I just responded to that. There's another girl who said, like, "oh why aren't the Arab countries taking refugees", and I clarified that, "actually a lot of them did". But I did clarify, a few times, different things on Islam and that sort of thing. 


\section{Zainab recounted:}

In classes I am [taking] usually.... because I am taking Political Science, a lot of courses that I have taken had been focused on ethnic, cultural concepts. So I find that in those courses there is a sort of misinformation that other students might say, and I found myself, in the past, because I have some knowledge of the issue especially when it comes to Islam. I have been able to stick up for the faith in that way. That's one way I sort of found a way [to] clarify misconception[s] the people might have. This happened once or twice, even in [a] Master's level course; somebody was saying something about the niqab ban that went through the citizenship ceremonies, and I was able to talk about how it wasn't statistically, there was less than $1 \%$ of women actually [who] wore the niqab to the ceremony. So it's not really a big threat etc., etc. So finding ways within the classes and these spaces to talk about my faith and clarify misconceptions the other students might have, not necessarily the professors, what students believe and think.

While most students tended to respond to overt, offensive, and Islamophobic remarks, it has been argued in Cole and Ahmadi's research (2003), that peer interaction is often influenced by fear and suspicion, which constructs feelings of alienation, isolation, and ethnocentric assumptions towards veiled Muslim women. Although classroom discussions should be stimulating and challenging, students have the right to express their opinions. If such discussions are not monitored or managed by professors, they could turn into a tool to ridicule and lead to discrimination toward Muslims students (Speck, 1997). The findings from this study added to the literature because the majority of the participants felt subjected to Islamophobic sentiments from their classmates. According to the interviewees, part of a professor's classroom responsibility is to intervene if students make insulting comments about a religion. Another student alluded to the failure of a professor to intervene when she related an incident in which students ridiculed the Quran. Lack of intervention and systemic silencing contributes to the invalidation of the lived experiences of Islamophobia. Discriminatory and Islamophobic attitudes on the part 
of students are often encouraged by professors' lack of response. This can lead to isolationist attitudes, as revealed in my interview with Lina:

Having to... especially when we have class debates, like, I remember first year of political science, having certain students not really be sensitive towards the issue, so kind of saying, "oh like the Quran says..." I remember this really distinctly [from] my first year political science class; someone said "doesn't the Quran say that you're supposed to, like, break down tall buildings?" So they were referencing, like, 9/11, and then I was like "Okay, wow, like you are a university student, and you believe that". It's so bizarre to me that's someone logically thinks like that. But then just seeing, like, my professor not even say anything towards that or defend or explain it in any way and me having to speak up and say something instead of like my professor who's supposed to facilitate those conversations or my TA is supposed to facilitate those conversations.

Some of the South Asian women in Bagguley and Hussain's research (2007) felt that they suffered from racism within the educational environment from fellow students, and much of the racism was in the form of Islamophobia. Anti-Islamic sentiment in the classroom can also contribute to feelings of isolation among Muslim students, especially if a student is the only Muslim in the class. Students' remarks were also ignored by professors. When they raised the issue with professors, they found that the professors were reluctant to intervene, leaving them to deal with the situation themselves. Similar to Bagguley \& Hussain's (2007) findings, my study revealed that professors fail to intervene to correct students' misconception and ridicule of Islam. For instance, another Muslim student referenced their experience in a political science course where there were Islamophobic comments made by fellow classmates, and the student expected the instructor to step in and facilitate the conversation. However, this did not occur. Several students shared their experiences of Islamophobia in the classroom, and due to lack of intervention by the instructors, they were left on their own to figure out how to represent their faith. 
Many of the Muslim students reported overhearing racist and Islamophobic comments from classmates in informal spaces before and after class. The Muslim students shared experiences of overtly offensive comments. Words are the most common weapon of bigotry and discrimination. Since the comments were made in informal conversations they were unable to respond to them. Zainab described her experiences of Islamophobia at undergraduate level, an account of the woman who wears the niqab (face-veil). She states:

I did have students in school who were, like, outright racist. I remember there was a particular incident that happened: there was a guy... it's funny because he was an Egyptian Coptic, he was blatantly Islamophob[ic]. I remember in my first or second year of university, because we were in the same program, we would tend to have a lot of classes together, and I am standing in the hallway, and he walks with one of his friends. He is standing there, and he knows I could hear him; he's like "I don't know why they wear these things, you can't tell if it's a man or a women underneath there, it's scary". The girl he was with, she was really embarrassed. She's like "you know you're being very loud in front of her".

Racist and Islamophobic comments also appear on students' Facebook timelines, as is the case with University Confession Facebook page. Although Aisha had never experienced any form of overt Islamophobia on the university campus, she describes an incident, which occurred off campus, referenced on the public Facebook page:

There is a Facebook page, a confession page where you can confess things. It's supposed to be for academic confessions, but sometimes people confess very troubling opinions. They confess being very homophobic, they will confess being anti-dark-skinned people, they'll be like, "why am I going to school with a horde of Asians?", and they would say a lot of Islamophobic things, and my friend subscribes to that page, so she sometimes comments on various things. She says that she receives a lot of [Islamophobic comments]. That is the page where a lot of people think that they can be very racist, sexist, very homophobic, and Islamophobic, maybe they are, they just don't show in real life as much. 
The Facebook Confession page is a disturbing place where it fuels Islamophobic and discriminatory discussions, and consequently it is part of the university experience; although this is the case in many online platforms, where the internet users can express themselves more freely. The range of settings where Muslim students are exposed to these comments sheds light on the extent to which Islamophobia is a problem on university campuses.

\subsection{Muslim Student Experiences with Student Services}

Participants were asked to indicate whether they felt Islamophobia and racism in their universities on the side of the student service providers. Some of the female participants were very critical of student services, who had shown a lack of interest in Muslims students. In the U.K., the stereotypical attitudes of school counselors about Muslim female students are highlighted by Sianna and Clark (1992). The researchers argue that the academic counselors held biased and stereotypical views about Muslim female students as not interested in pursuing higher education and career opportunities. The participants found several barriers associated with academic advisors and pointed to the issue of unequal access with students from culturally diverse backgrounds. Although in the interviews, the student services were seldom referred to, but the experiences that the participants reported about their interactions with student affairs or other service providers are crucial to the student's academic success and how students develop in their journey while at university.

Muslim students felt that they were discouraged from pursuing advanced degrees in challenging fields. While usually the comments are not made explicit, stereotypes about their race or religion as less intelligent or incompetent to handle certain majors 
were perceived from the student service provider's behavior and academic advisor.

Maryam shared her narrative of using career counseling services, in which the counselor

demonstrated an act of favourtism. Maryam felt her experience with the academic

counseling was alienating and pervaded with the feeling of 'Othering'. These were

descriptions of the process of meeting the academic advisor:

Last semester I wanted to apply to Audiology at [several universities]. I went to the academic counselor for psychology and just specifically talked about which courses would help me with my overall GPA perhaps and how to go about it;" and I went there. There was another student who was already inside and she was discussing grad school, and she was of a different ethnicity and she looked nothing like dark hair. I could hear their conversation because the door was open. It wasn't a private conversation so students were waiting outside, and it was more so telling her what she should do, what she shouldn't do. The conversation was a lot like more light, she was more open with the student. She was telling her where she can go, and she was looking up the websites: "oh you could do it, why won't you look up this professor's research they're doing so why won't you contact that professor from so on university?" So the conversation went on for a long time, and I was really excited. So, I am like "okay this is good", maybe she will be able to help me, and when that individual left, and when I went [in] right after her and told her that I'm thinking of pursuing grad school, she didn't really... she was like "ummmm", and it was like nodding, "so what would you like me to do", and I was like, "okay well I would like to [take] these courses. I just want to make sure, do you think I should change anything? This is what I need for audiology; is there another course that will be less stressful? I need to take this because I want to make sure my GPA is good enough". There was not a proper response. It wasn't... she didn't go on her computer to look up; I had to ask questions in order to get an answer, and you just know the body language is closed, and I understood, and it's so funny. I understood it as if it has happened before and my body language is like, okay, that's fine; it is what it is. Let's see what happens.

Muslim students bear a double burden as they navigate university environment, while processing the instances of racial and religious injustices. Perceived discrimination makes it difficult for Muslim students to engage with their campus and utilize the resources in the way that their white peers do. Maryam felt that she was not served as she would have preferred. This situation is one that cries out to be addressed because it alienates her from 
a potentially helpful service. This instance illustrates that the discomfort a student senses

can be the reason she stops seeking services, despite needing the support to excel academically. This was echoed by the Muslim South Asian participants in Tyrer and Ahmad's (2006) research, who have been 'Othered', where they felt their academic advisors did not support their interest to pursue professions such as medicine.

Lina had a similar experience as Maryam, who referred to student services for counseling. In a more detailed account, Lina shared her concerns of being made to feel oppressed:

I've had certain remarks being made, like, I remember a counselor once saying or kind of like putting into doubt, like, a community and she would be like, "oh so". She would tell me she's like, "oh so you're involved with your mosque", and I said, "yes", and she was like, "okay and do you know your Imam?" and I am like, "yes, I do", and she was like "really how is he?" like you mean are they kind of implying that their more restrictive or they're somehow oppressing or oppressive. But the mosque I go to is really great and very empowering, so it was interesting seeing the [negative] connotations [associated with Imam]. But I don't know it stems from ignorance.

One aspect unique to Nadia's experiences among the eight case study participants was her perceived direct encounters of Islamophobia on the university campus on the side of the student service providers at her faculty. She provided the details of the incident that led her to assume this position:

I went into the Bachelor of Business Administration office, and I'm just talking to a front desk lady, but I remember she was so rude. She was like, "sit down over there", like maybe she is having a bad day, whatever, but I kid you not, the next guy who walked in, tall, blue eyes, blonde hair. But he walked in and he asked the same questions as me. We just wanted to see our Economic[s] Professor, and he's in the room, but we have to go through her to get into the room. He asked the same thing, "Can I see him?" I swear to God, this lady is like, "oh yeah, like, go ahead, like, don't worry", and I mean that just made me like, "I've never experienced that before", so I was actually so upset, like, I don't even think I stayed, "I'm just gonna 
leave, I'll see him tomorrow when this lady isn't there", but I definitely remember that.

The richness of comments provided by the participants of this research go far beyond what existing literature has had to offer in terms of Muslim students' experiences with student services at the post-secondary level of education. The experiences that these Muslim students shared imply a problem of experiencing an Orientalist gaze, a theme that has been woven into the analyses of all of the relationships in this research.

\section{Strong Religious Identity \& Resisting and Challenging Islamophobic Sentiments}

This section is divided into three sub-themes. The findings show that rise in Islamophobic discourses and acts prompts: (1) Strong religious Identity, and (2) Resisting and challenging Islamophobic sentiments.

\subsection{Strong Religious Identity}

Strong Islamic identity is a key theme throughout this research, highlighting the change and/or entrenching of certain anti-Muslim notions within the articulation of Muslim identity. I was primarily interested in examining how Muslim students construct or navigate their identities subsequent to tragic terrorist events and the intensification of Islamophobia. This study found that Islamophobia immensely impacted the lives and identity-construction of Muslim students in the diaspora. This study revealed that Islam and Muslim identity are important to Muslim students, reflecting other research in this area (Jacobson 1997; Mac an Ghaill \& Haywood 2015; Samad, 1996). A great deal can be learned about questions of identity by paying close attention to the details of the individuals' interpretations of their own experiences. What emerged from an in-depth examination of their experiences is that Islamophobic discourses prompt Islamic identity, 
which is considered the best defense against Islamophobia, as students' lives are marked by an intensified global surveillance.

Based on my observations, Muslim students' narratives are inherently political in their message and portrayal of Islamic identities. Farida speaks of identity politics, "I identify myself as a Muslim black woman. I choose that designation because, I believe the way we present ourselves physically is more of, like, a story itself, so no matter what I do, like, I am...the first thing people see is my hijab". To a large extent, after conversing with the young Muslim students, I could see that their activism is grounded in spirituality, which is a coping strategy. These young Muslims felt engaged and empowered by the activities they participated in, such as fostering dialogue, contacting a local MP to reduce Islamophobic violence, attending a demonstration, creating an awareness, and being vocal in the classroom setting. An important byproduct of this was that this activism helped deal with the challenges of Islamophobic environments. Wiktorowicz's (2004) research represents a major study in the field of Islamic activism. His study reveals that Muslims and Muslim activists develop solidarity and collective actions through the belief in a vague call that Islam is the solution in an attempt to make sense of their social and political realities. The type of Muslim activism enacted by the participants of my study, as well as those discussed by Bullock (2002); Sirin and Fine (2008); Zine (2000); and Maira (2009) can serve as an example. The activism expressed by the youth in these studies is conceptualized as civic participation and social-justice activism aimed at bringing about change through education, which includes bringing attention to Islamophobic discourses and practices (Aslam, 2011, p. 15). 
The political global events and the wider political response form an essential backdrop to this discussion of the young Muslims' experiences of Islamophobia. Islamophobia, in particular, is tied to global processes and events (Hussain \& Bagguley, 2007). It is essential to contextualize the cases in relation to wider political tragic events. For this study, the young Muslim's experiences of Islamophobia were profoundly affected by responses to the recent global and local political tragic events. The development of the assertion of an Islamic identity can be considered as the outcome of political processes operating locally and globally, for instance, the war on terror (Mac an Ghaill \& Haywood, 2017). The response of the wider society was to demonize all Muslims, thus ignoring the complex set of different identities (Jacobson 1997; Samad 1996). In this case, the risk is that we have an over-politicized account. As we shall see, this approach can help us to understand the identities of our participants. Identity construction, according to Hall (1996), happens as a result of the relationship one has with the 'Other', and the differences between them that become not only highlighted, but also seen as significant.

The key issue addressed by this study is the understanding of why and how religious allegiance is coming to be a more significant and meaningful aspect of identity for these young Muslim students. In an era of heightened focus on Islam, it becomes important to explore the extent to which Muslims use or rely on political narratives to portray their identities. Reconfigurations of identity and rendering certain forms of Islam hyper-visible as a result of this jettisoning took further shape as Muslim communities acted in light of Islamophobic discourse, which permeated media and politics (Aslam, 2011). As Moghissi, Rahnema and Goodman (2009) assert, the representation of Islam as 
backwards and fanatical has led to a new group identity among Muslims in Canada, whereby:

We are witnessing the rapid formation of an overarching, collective identity or group affiliation that dis-articulates each of these communities from its specific origins, instead uniting them all as nominally homogenous 'Muslim' population. The marked national and ethnic diversity of these groups, along with their distinct political histories, cultures, and languages, suggests that it is neither nostalgia for a homeland, real or imaginary, nor the sudden discovery of Islam's moral and ethical values that motivates these populations to join together, but rather a commonality in the sense of being deported to the culture of non-belonging, of becoming (p. 13).

This vivid religious awareness and common purpose has characteristics that are worth mentioning. One is that it provides a strong sense of community, united by their common faith. It implies a feeling of solidarity with Muslim communities as it cuts across regional and national barriers. The motivation for becoming more devoted and attached to Muslim identity varies. Moghissi, Rahnema and Goodman (2009) suggested an alternative explanation to virulent shift towards identification with Islam. They argued that it represents an ideological tool to resist and respond to the Western hegemony, and has little if anything to do with an increased spirituality and connection to Islam; they point out the existence of a large group of secular Muslims who are misrepresented and alienated even further through assumptions made by non-Muslims about their religious motivations for being active. Similarly, Sirin and Fine's (2008) study of Muslim youth in the U.S., found that spirituality and religion was the most common coping strategy employed by youth in dealing with the challenges of living in a post-9/11 environment of Islamophobia and discrimination. Similar to the participants in this study, Sirin and Fine (2008) found that not only were religion and spirituality used as coping mechanisms by the youth, religion also gave context to a bigger picture, which is the meaning and 
purpose of life within which we are given challenges as tests of faith, and thus opens up new vistas of hope. This speaks to the view held by Farida:

I identify with my religion for sure, and the reason of why I identify more with my religion is because I believe, like, I believe our bodies are obviously here temporarily, and I'm a very spiritual person so my soul, like... I believe in, like, obviously the afterlife. So obviously I am a Muslim because being Muslim simply just means you're a believer; you believe in one God and believe in the message. I hold Islam and being Muslim more closer.

Religious identity and practice were significant to my research participants' social status and belonging in campus culture. The significance of religion lies in the fact that Islam, by and large, plays a central role in life for Muslims and who they believe they are: they affirm their belief in its teachings and regard it as something in relation to which they should orient their behaviour in all spheres of life, conduct of human affairs, and which, therefore, demands of them a self-conscious and explicit commitment (Jacobson, 1997). When Nadia spoke about identifying with the Islamic dress code, she explained that:

[it] is important for me personally, and my family too, but also staying true to ourselves and also following the Sunnahs of the Prophet [SalAllahu alayhi wasalam). But also reading the Quran, and pray 5 times a day, daily prayers, and being around... well I am from Toronto; we have a strong community back there in term[s] of Sri Lankan Muslims, so I feel, like, always being included and always being busy with community, Masjid related stuff. We're pretty active in our community and that's how I would relate Islamically to people. But with Islamic identity...I don't really want to look like, "a modern Muslim", but for me Islam is modest and as a woman I feel like.... you read the Quran, you really understand it, and you'd realize... God said stuff for a reason, so I definitely try to follow everything.

When the Muslim students were asked about their identities, I saw how they often talked about themselves as a Muslim. They immediately responded, "I am Muslim". This was a common response amongst the Muslim students, which corresponds to other research on 
the way in which religious identity is increasingly significant for young Muslims

(Jacobson 1997; Samad 1996). Muslim identity is very essential for Adam:

My religion has become more of an important part of my life since then. I think I have become more practicing of my religion because when people say of their identity, they kind of say what they consider most important first. So, I mean, for some people their sexuality will be ranked as the first thing, for other people it will be their ethnicity, but I think now in my life even for the past couple of years, I think my religion is what I would say first. Before that I would first say I was Canadian first.

These students expressed pride and satisfaction in their Islamic identity and drew strength from their religion. They re-interpreted what their Islamic identity means to them personally. As it is evident in Hamza's comment:

I think for me no matter what happens in the world, like I'm going to do what I want to do in that sense that nothing can change that, and I am not going to compromise my faith at all....... I think, like, everything that happens, I'm more proud of my faith and more proud to keep my faith, and I think these are all like barriers that have come between people and their faith and [are] all tests and like there's no need...there is definitely no need to be ashamed because if you weren't involved in doing anything then you shouldn't apologize or be ashamed of it.

Islamophobic sentiments had a positive impact on Farida's identity:

I feel like [Islamophobia] has been such a positive impact on my academic performance because I love knowing that one day, like, I'll be able to achieve what I.... I will be able to achieve as a Muslim woman. I feel like it encourages, gives me more of a purpose. Being a Muslim or this whole push up people like hating me simply because of the fact that I am Muslim pushes me more to prove them wrong.

Farida highlighted the positive attributes of Islamophobia, similarly in Alfred's study

(1997), many African-American women faculty members defined their marginal position as a positive attribute rather than feeling 'inferior' or 'victimized', many women drew strength from their ability to watch and learn the behaviour of the dominant group. 
Examining various factors contributing to the formation of Muslim identity, I asked participants about the factors that contribute to their Islamic identity. When probed further, Adam mentioned:

I think the experiences that has been going on for the past few years turned the people the other way, referring to Islamophobia and things like that, in that sense people want to be kind of.... people want to distance themselves from the community, but I don't know, maybe that's made me more in touch with my faith that people are attacking, but I'm going to claim it more. I'm going to represent my faith and kind of change the opinion of people about it.

Adam sees the prospect of an assertive Islamic identity in the context of an increased focus on Islam:

When the War in Iraq happened, all these different things that seems to be attacks on Muslim identity. I began to understand my Muslim identity as sort of a distinct item. And I guess that was something all seen by constant attacks on Islam as, like, a terrorist religion and that sort of thing. And I learned more about Islam and I became more religious actually because people would attack it, and I try to look up the defenses or the responses to that.

Due to what is happening in the media and the propaganda against Islam and Muslims, the participants needed to first educate themselves and then others. Nadia echoed this in a similar response:

I feel like I am more firmer with my identity. Like, as a kid growing up, I was bullied a lot; I felt lost with who I was, the question of who am I, really resonated on me. Today I feel like, despite it being hard and all, I feel like with the events that have occurred, it has definitely given me the strength and the confidence, like, express myself in my way; its giving me more of the confidence to proudly identify myself as Muslim, and not only change things for myself but to change things for, like, sisters like me.

After September 11th and other recent terrorist attacks, many had to face questions about their religion and what it means to be a Muslim in contemporary society. Maryam points out: 
Actually for past, ever since Harper [proposed ban on niqabs], making into one his campaigns that's when I also started questioning, "what does it mean to be a Muslim?" Is it something... do I want to be and why do I want to be, because I was seeing myself as now the "Other" again. I took my Islamic heritage, also, for granted, it's just who I am, but why else talk about it then? Seeing it again people asking me or listening to others who were non-Muslims, and again made [me] question what does it mean to be a Muslim.

The consequences of the politically charged events solidified Islamic identity, as it is evident in Maryam's statement:

Because of the incidents that are recently happening around me, it seems like there's a lot of attack[s] on Islam through media and that makes me feel like I have to protect that part of my identity more, and so then I'm justifying or at least questioning and by doing so it's actually making me close to my religion.

As evident in the above quotation, Islamophobia had a crucial impact on developing who she is - her identity. She expressed a sort of appreciation for the struggles she had encountered. This development of identity, of growth in the self-knowledge, and further, their knowledge of Islam, has resulted in a greater confidence. Furthermore, the negative discursive representation of Islam pushes Muslims to claim their Islamic identity further and make their voice heard. In the context of Islamophobia, I found that as a whole, the participants' identity as a Muslim has been strengthened. Overall, the negative discourse of Islam has solidified their Muslim identity.

The experiences and climate for Muslim students is permeated by current world events and U.S. foreign policies that have drawn national and international attention to certain religious groups, specifically those rooted in Islam. The Western society's interest in Islam has extended to university campuses, where Muslim students have likely become more visible and active as a result (Cole \& Ahmadi, 2010). This is particularly perplexing given this era of globalization. The U.S. travel ban on individuals from several Muslim 
countries, and arguably, the resultant growth of Islamophobia and xenophobia that have since become commonplace for Muslims in our society.

In the current climate of Islamophobia, Muslims have become thirsty for knowledge of their own religion. Muslim voices are needed to counter these prejudicial attitudes. They are expected to promote accurate content knowledge of Islam. Muslim students were keen to enroll in courses on Islam, Muslims, and Middle Eastern politics. But in a troubled and politically charged climate, these courses could be psychologically stressful environments where Muslims were already subjected to critical and academic scrutiny (Mir, 2014). Islamophobia has impacted their lives, and one visible effect is that they became more knowledgeable about Islam. As Adam states:

So I think the big thing was, like, when ISIS rose. There was a lot of questions about Islam and a lot of questions about identity that I had, and that was my second year, and so I was researching about a lot of these things, until the big thing for me was that when I was really started to have an interest in this topic. I was really afraid of being put on a watch list. So, that was, like, the big thing for me.

Most of the participants are fully aware that Muslim communities are under scrutiny and thus need a better understanding of their own religion. Lina also points out:

I think being younger I was often very uncomfortable with my identity and with who [I was,] so kind of just hiding away, like, parts of my religion, like seeing what's happening in the media and things like that. Like, I felt kind of like ashamed to be Muslim.... to be Afghan especially, like, with the wars that were going on. But then as I grew older, like, I understood, like, the rhetoric, and [it] became something that I was interested in learning more, even, like, the major that — I'm in Middle Eastern studies...because I was so uncomfortable with my identity, wanted to learn more about Islam and, like, other religions and the Middle Eastern Region and history, things like that.

Many second and third generation Muslims now identify more strongly with their religion than with some kind of ethno-national origin (Jacobson 1997; Samad 1996). 
Maryam states that "I am becoming closer to the beliefs of religion because culture is important, but at the same time when you're living outside away from a nation then it becomes hard to.... I guess more towards faith”. Being Muslim is seen as a more fundamental source of identity for Muslims than ethnicity. Islamic identity is perceived as almost overshadowing other identities, rendering them insignificant. Although other identities undoubtedly shape many of their experiences and their responses to those experiences, it is not seen as the basis of an all-encompassing frame of reference that explains or forms their place in the world. Despite the Islamophobic reaction of mainstream Canadians, Muslims have learned to cross ethnic boundaries and view themselves as Muslims first. Hall (1993) highlights the complex process through which cultural identities evolve, in his argument:

Cultural identities come from somewhere, have histories. But, like everything else which is historical, they undergo constant transformation. Far from being eternally fixed in some essentialist past, they are subject to the continuous 'play' of history, culture and power ... cultural identity is a matter of 'becoming' as well as of 'being'. It belongs to the future as much as to the past (p. 394).

Adam clearly indicates in his statement that ethnicity/race is less significant, while developing of an assertive Islamic identity is empowering:

I identify more with my religion, I've always seen ethnicity or race as something pointless. It doesn't actually hold any meaning. It's just something that you're born with. But religion, it should be something that you choose; it is set of ideas that actually influence your life.

Clearly the second-generation young people do not associate themselves with their ethnicity.

I used critical race theory as the foundation to interpret my participants' narratives. However, applying critical race theory to examine issues around religion 
might be restrictive and problematic. Some critiques of critical race theory posit that this theoretical approach focuses race as a focal point to understand inequality, while dismissing the complexity of other factors, such as religion (Cole \& Maisuria, 2009). In short, religiously grounded normative arguments are not advanced in CRT. Race is a socially constructed concept, which is an ideology of white supremacy and dominant groups to classify humans based on skin colour (Carr, 2006). Islam is a religion whose followers come from different ethnicities and backgrounds. Muslims are one of the most heterogeneous populations in the world. Identifying Muslims is not an easy task, increasing numbers of African Americans, and Caucasians convert to Islam and this complicate the idea that Muslims are phenotypically Middle Eastern. The repercussion of the Islamophobic bigotry shifts into level of dangerous actions towards anyone that have Muslim attributes or someone who is dark skinned. Islamophobia does not necessarily fit with the 'Eurocentric' concept of racism. The participants in this study experienced oppression on the bases of their religion and also because of their physical appearance. CRT cannot provide sufficient insights into experiences of some Muslim students. The narratives of some participants imply that religion plays a significant role in their experiences of racism and Islamophobia. Nadia is also not comfortable navigating the Sri Lankan culture; growing up in Canada with a sense of being Muslim Canadian, she is unable to identify with her ethnicity. Thus she demonstrated an assertive Muslim identity:

I identify with my religion $100 \%$. Honestly, like, I am not trying to say I am not proud of being Sri Lankan, but I don't know what that is. Like, my dad came to Canada 25 years ago. He left behind Sri-Lanka for his own reasons. I mean it's sad, but I don't really know his side. Even when we go to the weddings, you know the typical "Tamil people"; it's so hard to identify as Sri-Lankan. I don't like the culture because I wasn't born or raised around that. It's just Islamic culture for us [that] is very important. We['re] gonna pray 5 times a day, we're gonna be good people, 
we're not gonna drink or eat pork, but at the end of the day, like, we're here to better serve the humanity, and I think that's what we're all striving for. But no, I wouldn't consider myself as...again I would never like touch on culture, like "oh I am Sri Lankan". But at the end of the day, I would identify as a Muslim, that's the most important thing.

From what was stated by the participants, it is evident that the concept of ethnicity sets certain limits on one's potential to redefine oneself. For this project's participants, ethnic identity is mainly given or natural, by being born into it, and not the country of origin. While religion, is regarded as matter of personal choice, and it is based on reflection and on self-conscious determination (Jackobson, 2006). While older definitions of race and ethnicity have biological and cultural bases, respectively, the participant's responses of race and ethnicity have blurred this distinction. As is evident in Adam and Nadia's statements, many of the young Muslims do not identify with their ethnicity as much as they do with their Muslim identity. This is consistent with the findings of several studies (Jacobson 1997; Mac an Ghaill \& Haywood 2015; Samad 1996). Several participants in this study asserted that religion has become a source of collective identity in response to Islamophobia, an escape from the oppressive tedium of being constantly identified in negative attributions. The first emphasizes the distinctiveness of religion as opposed to ethnic identity. In this view religion, Islam is universally relevant and applicable, whilst ethnic identities are particularistic and associated with tradition or culture. Furthermore, ethnicity carries connotations of a sense of origin, whereas Islam brings a sense of belonging to a global community — the umma (Hussain \& Bagguley, 2007). This finding is consistent with the findings of Gardner and Shukur's study (1994); they have written in relation to British Bengalis, asserting the fact that the 'collective ideal' contained within religious rhetoric is not confined to Britain, but is meant to encompass the world, and this 
can be a powerful motivating force in acting in collective defense of a Muslim

brotherhood. It allows these young people to feel that they are part of a worldwide trend, which links them politically to the global umma (Jackobson, 1994). In this way, the boundaries defining Muslim identity may also be strengthened since religious identities are globalized: the young Muslims are likely to feel that although within British society they are members of a relatively small and weak minority, their religious beliefs and practices traverse the globe and history and are, thus, components of what is a vast and powerful force (Jackobson, 2006). Commenting on the bearing Islamophobia has had on young Muslims, Bayat and Herrera (2010) discuss:

Whether as radical or moderate, principled or pragmatic, the current cohort of young Muslims constitutes the globalized generation of the post-9/11 era that has felt, experienced, and been overwhelmed by the overbearing politics and discourse in the West that prejudice Islam and Muslims. Very simply put recent Islamophobia in the West has rendered even 'secular' youth in Muslim societies to identify with Islam (p. 21).

Upon careful examination, a resurgence of Muslim consciousness means that Muslims, in a particular socio-political context, are distinguishable, and thus forge Islamic identity, which serves to be well represented. The latter religious identity will become more habitually foregrounded when they need to organize communally to obtain recognition to address specific needs and find themselves the object of similar discrimination. This is due to their common faith, as this creates new group boundaries of "us versus them" along a religious axis (Bloul, 2008). Not surprisingly, this study found that prejudice against Muslims, in the wake of Islamophobia, has led to strengthening of bonds and solidarity within the Muslim community and a corresponding predominance of the 
religious factor in their consciousness. Lina speaks of collective identity and solidarity,

and argues that Islamophobia creates unity as Muslims are united against Islamophobia:

I think it also heightens our awareness, so makes it more important for us to make sure we have a solid understanding of our identity because if that can break us down then... I don't know, so it's important for us to make sure our identity stands strong and we are able to dispel any misconceptions about what we believe. It also creates like a sort of unity within the community as well because we are against Islamophobia, and we are united against Islamophobia so it solidifies your identity even further. And for some people it is the opposite where it just makes them not even want to practice, not even want to believe because they're like my religion preaches hatred and this is what I'm hearing and makes them go off track. Because I am involved in the Muslim community, I would say it makes us more unified against those things. Like, we've arranged vigil, we arranged protests, we arrange things like that kind of like bring us together against horrible incidents like that, so I always see that more often like I see activism on Facebook and Twitter and those things more than I do see people, like, turning away from Islam.

Adam also reflected on the state of solidarity:

I think after terrorist attacks there's more solidarity, and this sort of a unified thing of like "damn, this sucks", and I think a lot of times when, for example in the [previous Prime Minister's] campaign happened and they're being really antiMuslim. A lot of Muslims felt the passion and they mobilized to work against that. And I think after a lot of terrorist attacks, a lot of Muslims have a passion for either questioning their faith, which is one, or have passion for either like making up for it, so, like, trying to [be] for example apologetic to an extent, like not necessarily submissive or trying to like make it clear that we don't support this, so, like, for example the Orlando night club [shooting].

These issues are important, as they concern the identity positions from which the young Muslims approach higher education and experience life in universities. Their identities are central to their positions within communities and how these positions are changing, both as a result of their own education and as a result of wider social, cultural, and political forces. Their ethnic and religious identities and how they are expressed affect their experiences of racism and Islamophobia (Hussain \& Bagguley, 2007). In fact, while racism and Islamophobia challenge the collective constructions of identity among 
Muslim students, the process of combating these negative constructions of difference provide, at the same time, a greater impetus for collective mobilization through formalized resistance (Zine 2000).

\subsection{Resisting and challenging Islamophobic sentiments}

An important theme that emerges from participants' answers is that the recent national and international tragic events and Islamophobia have created further pressure on individual Muslim students to justify and defend their faith and identity when interacting with non-Muslims in educational institutions. Lina, a Muslim undergraduate, described the situation in the following way:

You always have to clarify and defend what you believe and that's where the issues come from, and then as you progress you tend to realize that that's what makes me unique, and that's what you have to continue with, despite how different you may look to other people, despite how like odd. So I think before I used to hate trying to defend and, like, explain my religion and my identity, whatever, but now I enjoy doing that because it's a way for others to understand who I am and understand other Muslims like me.

The pressure to answer for violent attacks carried out by Muslim perpetrators has driven some young Muslims to pull away from their faith, while others try to recapture it. Some of the participants shared their frustration with defending one's faith: "we have always been forced into a position where we have to defend what we believe. I wouldn't say a burden, but it can get very tiring, but that's kind of, like, the mission". They found this to be a particularly isolating experience.

Young Muslim Canadians feel a strong societal pressure, and feel saddled with a responsibility to have to respond for atrocities perpetrated by radical terrorists in the name of Islam: 
It rages me; it makes me so angry that people are filled with so much hatred, like how can you take such a beautiful religion and do horrible things in the name of it, so that's kind of like my anger towards people who do commit those things, and at the same time it's disappointing too because I don't constantly want to say like "oh Islam is a religion of peace, we don't condone these attacks". I constantly have to say it after every single one of... like, whether it's San Bernardino, whether [it] was, like, the night club shooting, whether it was the Paris attack, so I am mourning too you know. I'm mourning for those victims too, like, I did not take part of it; I did not support this a group of people. [They] don't represent an entire religion so that's disappointing to me.

Maryam made an excellent point that "Muslims are still stuck on [proving that Islam embodies a religion of peace, and it's limiting, as] we are not able to progress, nor can we focus about other important issues". She further elaborated:

It's hard to be able to progress like personally as a Muslim individual when you have outside pressure of constantly saying if your religion is good or bad or what are the basics of it. For instance, I follow Amina Wudu. She is feminist, and she believes in inclusiveness, so it's hard to follow that when you have so much outside stuff you have to worry about, like Islam is terrorist, support ISIS, or Taliban. It's hard to try to maintain. Like, no, that's not all true, but let's concentrate on progression, let's concentrate on women's rights, let's talk about gay rights in Islam, it's hard to do that when there's so many other things asking for your attention so that's the obstacle.

It is clear that the participants do not think lightly of the challenges and possible intimidations due to their participation in educating and enlightening Islamophobic misrepresentations; yet they still made the conscious choice to pursue these goals. These challenges demand considerable amount of energy and time. Farida, mentioned that she has continuously tried to defy the stereotypes about Muslim women and Islam, as she explains:

Already having the assumption, like, I can't be vocal about my opinion, simply because the fact that she might be oppressed or she might already be married when she was sixteen or the whole stereotypes that are glued to me, always having to unglue that. It's always a challenge with people because getting into debates and 
getting into arguments, speaking to people, it's never easy, having to explain yourself like why you believe in God, why you cover up. It's Canada you're free, [I say,] like, "oh no, I am free; I chose to wear this".

Maryam echoed Farida 's sentiments regarding the heavy burden placed on Muslims:

It's really disheartening. You have those very low days, or you just go like I wish it wouldn't be that of our part of the world, which means people will point at me again, like "you are responsible, you have to explain yourself". It does daunt you a lot, because you take it as a personal project, all of the sudden because people want you to take it as that, and you start to feel like "now I have to baby other people's emotions". I am in this too. I live in this part too, but somehow I have to turn in and cater to other people's emotions.

Canadian Muslim youth are being forced into defensive posturing, apologizing and constantly under suspicion. Most of the participants felt it was absurd to generalize an entire group based on the actions of few extremists. They are expected to defend their faith, and they do this by not remaining silent in the face of Islamophobia. This has placed serious stress on these young minds. To have to constantly defend one's faith, to continuously be called upon to condemn the actions of criminals and terrorists is emotionally draining and torturous, which no one should be subjected to.

A recurrent theme in this research is taking an active role in countering Islamophobic rhetoric. Issues of voice, the desire to educate, activism, and representation have been addressed as part of the collective goals of Muslim students. Islamophobia stimulates the emergence of new political identities, actively engaged in counter-struggle, ultimately re-defining the parameters of their social environment. Maryam states, as a Muslim Canadian that her role is to be active, and to have a voice:

These incidents, when it happens, you go like that's not who I am, I am not a face just to say "you look like so or you can't go to grad school or there are so much negativity around, you come from a very backward culture or you're oppressed". I feel, like, I have to be more socially active, I have to take a role of being aware of my surrounding, what is happening, what is the law, what's going on with the 
community and how can I approach. Actually, a lot of my Muslim friends from [X University] are active. They do go out and they attend these social activities, where they talked about it and they try to spread awareness. I'd see them as role models, I'd see that as something, we should all be doing because it matters, we need to have a voice.

I inquired about the strategies Muslim students employ in order to cope or navigate their environment in the context of Islamophobia:

I feel like right now what happened with Quebec, because it just happened most recently, I noticed a lot of activism within my circle of friends, that we're like "okay we're going to call the MPs, we're going to ask them what are you guys doing to make sure the Muslims are safe". Like, now this has happened, a lot of us, the fact that it happened in like... people were praying, for us it's something its very common, and someone can come in and just do this to completely innocent people; like it's a very frightening thought. It's so relatable in that sense that we all go to the mosque and pray. That's something should be a safe space, has become... like people are now saying, we need more security, more cameras. I have been also brainstorming ways we can speak to our MPs about more protection for the community; not just that, but for the long term security and safety of the community, like this kind of Islamophobia rhetoric that we see within the news for example; like how can we find ways to curtail it, ways to make Muslims look normal in society, basically not be looked as foreign to this country for example.

Participants did display a victimized perspective in their experiences, but illustrated their agency and, in many cases, strength of character. Students are not passive receivers of Islamophobia, but can be seen to engage in and even challenge these discourses of Islamophobia and alienation. For instance, Nadia reaches out and speaks about Islam through her spoken word:

I am seeking opportunities that allow me to express both sides with, to hopefully open people's mind. I feel like, we are in a world like where social and the media outlets really take over, and I pretty much just use that to seize opportunities within Canada, for example, so that I am able to create networking and create bonds with people who don't know much about me or about a lot of people like me. I recently had the opportunity to work with Vice Canada to speak on behalf of oppression of Muslim women in Canada, oppression that people give Muslim woman. I started reaching out to people through my spoken word, to kind of speak more about Islam. 
Zine (2000) in her discussion on Islamic subcultures, as a form of student resistance to

Eurocentrism in schools, articulates that the social infrastructure of interaction, cohesion and support is a key element to Muslim youth organizing of this form. Lina, whose activism involves work with the MSA of her university, echoed this trait of the group, commenting on some of the personal benefits to being part of this activist group. According to Zine (2000), this form of organizing achieves collective agency and makes use of positive peer support in response to an environment, which often excludes them. Lina discussed her involvement with the MSA:

Always trying to explain things to people or trying to raise awareness, and that's one of the things that I do through the MSA too. Even our Islam Awareness Week, where we put efforts towards educating the campus community and kind of like creating that cohesiveness that's something that I've learned from, and that's the role that I take on campus, kind of like constantly advocating, talking about issues of the marginalization, discrimination, things like that; that's what I think all Muslims have begun to strive for I guess.

All of the participants felt responsible for challenging Islamophobia. The participants I interviewed also expressed this concern. For some, this responsibility was formed around the issue of representation; they feel the pressure to conduct themselves in a specific way since they represent the Muslim community. This motivates them to attempt to be the best representative of Muslims by the way they had lived their lives, or exert this kind of effort to counteract stereotypes. In addition, the participants also felt an undue pressure to project themselves in a polite and friendly manner at all times in order to counteract the narrative of Muslims being inherently angry, dangerous, and violent. Farida advocates having inspirational Muslims in the spotlight to speak on behalf of Islam. All participants relate their experiences about enlightening others, about what Muslims are like. Maryam points out: 
Even if I am talking to my professors outside of the class, I do to let them know, directly or indirectly where I am from.... yes, I do mention it, not because I feel like they should know. They should know this is who I am and in a way to express myself, that I exist. Or when I talk to my non-Muslims, when they meet me first time, in the first or second conversation, I'd bring it up that I was born, or I am from Afghanistan, or the Afghan culture, so, just, I let them know that we exist and we are normal people and this what we look like.

She recounts that her professor proclaimed to be Muslim at the beginning of school year:

When I see professors that say that they're Muslims at the beginning of the school semester, I really like it. I appreciate that; I feel empowered. I have my physics Professor who's from Egypt. He said, "I am Muslim, I'd like to let people know". I like the fact that he mentions it; he makes that point right away and throughout the process and when he's talking... when he's talking about, let's say if in the conversations the word God will come up, he will use the word "Allah" just so it makes that it's not a scary word. It just means God and it's okay to say the word. So I felt really connected with that. I was happy that he did that, and I did notice that even with non-Muslims, they also felt like, "oh okay he's funny, he's normal". He says that "I get students to come to my office and telling me, like, you're not like the other Muslims, but how and what do you mean by that?" That's why I make the effort of letting people know that I am also Muslim or that I'm also an Afghan.

I asked what kind of environment does it create? She explained that:

It creates an awareness. You can feel that the environment gets a little more charged; it's charged with maybe perhaps curiosity, a lot of questions or even whatever people have towards that word "Islam" or "Muslim". It gets a little charged, then it creates a place for conversation, you can hear someone saying something, but it was a positive environment. It was not a negative; it wasn't like people were angry. People were like, "oh yeah, I have a friend", or they would make a joke, not in a negative way but in a way of 'let's talk about it': It's okay to be a Muslim".

Horwedel (2006) argued that since the perceptions of Americans about Islam and Muslims have grown increasingly negative, many Muslim students and faculty members in American universities are pushed to educate non-Muslims about Islam and Islamic beliefs. She emphasized the fact that while, some Muslims get overwhelmed and tired with this burden, others are happy to embrace or seize the opportunity to create an awareness and understanding. 
These acts can be seen to some extent as an act of resistance to Islamophobia. My study also sought to examine the resistance enacted by Muslim students in the university environment and to understand the motivations unique to their context. Zine's (2000) work on Muslim youth discusses the potential of schools to be a place for activism, through the resistance against Eurocentrism by Muslim students as they carve spaces for their own identities. Muslim Student Associations are highlighted as the mode and medium through which Muslim students can begin to develop Muslim subcultures in schools and challenge Eurocentrism. Resistance, as it is broadly conceived of in this way, can be seen as a means for students to claim a voice and enhance their presence and visibility on campus (Zine 2000). Zine (2000) argues that race and ethnicity are a basis for resistance as well. The resulting subculture in essence resists the marginal and subordinate positions created for Muslim students by Eurocentric policies and norms.

While some are socially active and counter the Islamophobic rhetoric by fostering dialogue, other participants felt a need to educate and inform non-Muslims about Islam. They saw the possibility of turning the negative attention to Islam to a positive opportunity to educate people about Islam. This is consistent with the findings of a number of studies (for example Khan 2009; Sirin \& Fine, 2008). For example, findings from Sirin and Fine's study (2008) indicated that many young Muslim girls who participated in their study felt responsible for educating other people to change their minds. They also highlighted this form of resistance amongst the participants of their study and pointed to their strong spirit. They stated: 'to challenge the assumption of "oppressed woman," these young women exhibit strength, authority, and confidence' (pp. 116-117). These comments resonate with Shain's (2011) work. These findings also 
resonate with Khan's work (2011); he highlighted the responsibility that many young Muslim Americans in his study felt the need to correct the prevailing negative stereotypes about Muslims and to re-present their religion in a positive light. A number of the participants in this study also felt responsible for educating other people to help them fix their impaired perceptions of Islam even though they recognized the difficulties involved in this responsibility:

I think as a visible person, my role is to educate people in the sense that as a person who is visibly Muslim. I feel like if someone asks me a question in the public for example, it has happened to me before where I have been on the bus or subway, people just sort of sitting beside [you]. Like, I remember a lady once asked me "do you wear this at home as well all the time, like, your hijab, do you have to cover it in front of your brother and stuff?" we had a good 10 minute of conversation. I accept that it's better for people to come and ask, as opposed to harbour some sort of ill will or grudge toward another person just because they have misconception about their belief. So I would see myself as an educator, especially in academia as well. I feel like we need to work on this rhetoric that says Canada is this amazing multicultural fabric; it's like a rainbow: everyone is from different places, and we all get along. Yeah, that's true, and especially when we see like how our Prime Minister is and kind of the way he speaks. But then at the same time there is a lot of institutionalized racism. People of color, black people, and indigenous people, they face the toughest times because of the barriers that are within the institution and that needs to change. And as a Muslim person, I think it's my duty to also speak up for these people, for non-Muslims who in these situations, who are marginalized communities.

Lina also felt responsible for educating others about Islam:

It is a responsibility on me, just because I do have or I'm aware of the dichotomy that exists, so just doing my best to maintain my identity throughout, and it would be difficult but that's kind of like the role that you have to assume just because of like the rising pressures that do exist, so rather than being, like, silent and not saying anything but educating in trying to create that awareness at least. That's my personal responsibility.

In the psychological views about racism discussed by Sleeter (2005), and mentioned earlier in this chapter, it is argued that education can help people overcome their biased misconceptions about people from different races and religions. Consistent with this 
view, participants in this study also believed that people are quite capable of revisiting their stereotypes about other people if they are educated. Adam also realized that people's negative perception of Islam is mainly due to lack of knowledge:

I've met, and I have had that where they've been convinced that Islam is this evil thing. And then, through conversation, I'll convince them otherwise and many have this view of Islam as being very distorted, but it doesn't come from a place of malice. It's not like negative attention; It's just a lack of knowledge.

It is also important to pay attention to the significance of systemic and institutional issues in discussing racism. As Henry and Tator (2009) argue "systemic racism refers more broadly to the law, rules, and norms woven into the social system that results in an unequal distribution of economic, political, and social resources and rewards among various racial groups" (p. 30). In this case, it is important to look at both individual behavior and institutional practices. Within the context of rising of Islamophobia, it is essential to educate individuals while at the same time challenge institutional practices. Islamophobia is understood as a fear of the 'Other', as Adam explained that the negative view of Islam does not come from a place of malice, it is due to lack of knowledge and understanding of the mainstream Muslim community. The Prejudice and misperceptions can be corrected by providing correct information of Islam.

Overall, through their activism the participants gained a deeper understanding of what it meant to be a Muslim in the context of Islamophobia, compelling them to take on the challenges of breaking down stereotypes about Islam and creating a higher level of consciousness in themselves about this aspect of their identities. The Muslim students discussed this desire to educate through creating awareness and engaging in dialogue. This is in fact akin to the Islamic notion of Dawah, which refers to the system of Islamic 
education that encourages the spread of Islamic knowledge through dialogue with nonMuslims (Zine, 2008).

The students interviewed made it clear that the goal and/or motivation behind their work was not to respond to Islamophobia through an explanation of Islam. Rather, they felt that there was a clear distinction between this and what they were interested in, namely, to critique, call attention to, and correct misrepresentations of Islam and Muslims. I was intrigued to learn that the youth maintain consciousness of the role they can play not just by critiquing various forms of Islamophobia, but also improving the situation themselves.

\subsection{Gendered Islamophobia}

A significant number of accounts highlighted experiences of Islamophobia linked to the hijab. This research took place after Trump's Muslim Ban and the Quebec shooting. Some of the participants suffered from the backlash of recent events, especially those who wore the hijab. The emphasis placed on hijab by many of the participants in their discussion of Islamophobia implies clear gendered dimensions to anti-Muslim sentiments. The participants' narratives illustrate how gender stereotypes inflict antiMuslim bigotry. The notion of gendered Islamophobia pertains to specific incidents of bigotry targeted at Muslim women due to the presence of religious apparel. It has its origins in historically contextualized negative stereotypes that inform and sustain the structural conditions of oppression. The re-emergence of gendered Islamophobia with the recent terrorist attacks often fixates on the bodies of Muslim women, inscribed as dangerous foreigners (Zine, 2006). Visible Muslim women tend to experience the most explicit and extreme form of Islamophobia, and bear the brunt of hate. This is due to the 
visibility factors, in particular, Muslim women who dress in the Islamic dress are readily identifiable. Out of the six female participants, three wore the hijab, one had just started making the transition from wearing niqab to a hijab. Most of them wore Islamic clothing such as the abaya. As clothing is often seen as an ethnic marker for many Muslim women, those who wore hijab with its connotations of what some believe is the "backwardness" of Muslims. Farida describes the hijab as:

Like, symbolically the hijab is almost like a fearful cloth. And the reason I say that, is because with Islamophobia, the hijab to many people is the scariest thing they'll ever see, because my hijab is, as if, like, it has many words printed on it, with the Islamophobic terms, the hatred, and the hate crime, and the hateful terms that they use. With Islamophobia my hijab is simply a dangerous, fearful cloth; that's just what it is to people.

The oppressive impacts of the threat of Islamophobic violence against Muslim women are wide-ranging. Farida, experienced this kind of extreme Islamophobia on two separate occasions, travelling to and from university:

I've experienced it first hand, and I think that's why I'm a little bit more vocal. It was last year, I was on a bus heading towards home, and I remember getting up; I was on FaceTime with my cousin from England, and Wallahi, like...this woman looked at me, like, "you're so disgusting". That's the first thing she said to me, and I looked at her; I'm like, "oh yeah, why am I disgusting today ma'am?" That's what I said. And she was like "you're disgusting, oh how she speaks English right now, go back to where you came from piece of blah, blah, blah", literally swearing at me. As she gets up, and spit at me, she spits at me, she goes, "you are so disgusting, you terrorist go bomb other places", and I honestly began to cry. No one did anything, the only time someone did something was when the lady got up to try to fight me, and the bus driver got up and try to keep his hands pretty much between. I called the 911. I'm like, this is what happened. They're like stand where you are, how are you telling me to stay where I am, where the same lady got off the bus as well. Three hours later... three hours later they came to my house asking, "what happened?" I'm like "Are you kidding me right now? Like, I tell you I'm a Muslim woman and I just experienced hate crime, like, somebody try [tried] to fight me. She spat at me. She verbally harassed me. I'm literally traumatized and you're coming to me three hours later?" I will never in my life forget that. I can literally cry about it today, which is kind of scary because the police, like, wrote all these 
things; they never even called me back. I called them, like, eh, I take one bus home, like, there's only one bus on my road. Like, what if I see her again? I can't take the bus home without thinking, like, what if this happens to me you again. Again, they were like, "just find another route, in meantime the detective will call you". I swear he called me like seven months later. I'm so tired of it, and because of that, like, I have become more vocal with anyone. Definitely, if anything Wallahi, like, it made me stronger. I feel like we are the new Jews of this world, of the century. All it's missing right now is the concentration camp.

Heightened Islamophobia calls for vigilance. Muslim women have to take self-defense classes. Farida's experience highlights the significance of the emotional impacts of experiences of overt forms of Islamophoia. Although Farida continues to wear the headscarf, frightening Islamophobic encounters in the bus and metro left her feeling apprehensive about going back to these locations for the next few months.

As with any victim of hate crime, Muslim women's experiences affects their sense of ease, safety, and belonging in their host country. Such violence is done on purpose, to encourage victims to (re) consider their place, to send a message that they are out of place. Nadia reflects on this:

With the recent terrorist events, it's only going to bring more fear, more anxiety. I today, like, I just don't think about myself. Like, I think about safety of everyone. I don't think anyone understand how scary that is, knowing the fact that today, like, you can't be who you are simply because of terrorist attacks that are going by the name of the Allah. Look, and especially with the president of the free world Donald Trump talking about Islamophobia so openly, so freely, should be an alert to humanity. So what, we're dangerous? We literally have the word "danger" tattooed on our foreheads. It's to the point where our parents [are] having conversations with their kids like, like, "Eh, if something happens like we might have to move back home". People who are born and raised in a country, don't even know their language, that they are supposed to like...this is their mother tongue. But the reason I am saying that, imagine, like, telling your kids, like, "We're moving back home". Like why? Like you're not safe here anymore. Somewhere where you revolved, or wrapped your life around and now you to move backwards.... to countries who were taken over by colonialism and then going back to like places that are broken.

The issue of safety was also echoed in Farida's response: 
Imagine being told that, like, you can be killed for it; you can be attacked. We hear many incidents like the one recently happened in London, where the woman was pregnant with twins: the guy punched and kicked her and her twins died. So imagine that it's literally like you're being told today that if you go out you're not guaranteed to return back. Hijab is literally like...It's probably the most strongest anyone could ever do today. Standing out today is scary. You're told to fit in, but we chose to stand up confidently too.

According to the observations of this study, the Muslim community lives in an atmosphere of fear in the context of Islamophobia. Several studies (Abu-Ras \& Suarez 2009; Kwan 2008; Perry 2013) corroborate the observation that this potential victimization has the intended effect of terrorizing and instilling fear among Muslim women - fear of violence, harassment, profiling, and a generalized fear of appearing in public. This concern was echoed by a non-veiled participant, Lina: "it creates a lot of discouragement within the community because they constantly feel limited by what they can do, and they're scared, and it creates, like, this environment of feeling terrified, when you should feel safe in your own country, but that's not what happens". Other participants I interviewed also expressed safety concerns. This concern was echoed across the board, as Farida explains:

I had a New York trip planned before March to go to [the] UN youth woman summit. Like, because of what's going on and what's being, like, told about, like, a lot of the Muslim women being detained and being put into interrogation grounds, my parents told me, like, I can't go anymore for safety reasons, and pick somewhere else. For me it is, because something that, like, I would've loved to do, like, for educational purposes; like, it's no longer something I can do simply because of the fact that I could be arrested or detained. Even though I was born here, they still won't care.

Managing their safety has become crucial for Muslim women. Consequently, the risk of victimization implies that women are forced to prioritize their safety over their education and expression of identity (Perry, 2013). In an effort to defend themselves from violence 
and victimization, Muslim women question the risks associated with their self-

presentation. For instance, Maryam deliberately avoided religious signs and emblems, reluctantly chose not to wear overtly Islamic symbols in order to feel safe. They are also forced to reconsider their visibility and have to decide whether to alter their performance of gender and religion in accordance with socially established norms. In this respect, Islamophobic violence serves the intended purpose of enforcing "appropriate" public performances and drive non-conformist members into the shadows (Perry, 2013). However, some reconsidered how they dress in response to specifically anti-Muslim comments and behaviour to the extent of considering alternatives similar to the hijab to reduce their visibility. The threat of Islamophobia forces Muslims to preemptively change their behaviour. Farida, who had experienced Islamophobia, was paranoid and has considered alternatives similar to the hijab, like a hat and hoodie, to reduce her visibility:

I think the stares are getting more and more uncomfortable, going outside is more so, like, you know like it's scary; it's really scary. Like, we are not safe here. It's so far that I bought a hat, so, like, when I'm outside so my hijab doesn't show, unless people are really looking.

By virtue of being a hijabi female, Muslim women experience becoming a primary suspect and internalizing paranoia consequently. This state of suspicion and paranoia illustrates how the discourse of securitization enters the social psyche through the operation of Islamophobia within a socio-psychological framework. Muslims themselves are overly conscious of their identity as suspect, carrying the added burden of proving their innocence, of denouncing acts of violence committed by strangers in the name of their religion (Saeed, 2016). This again illustrates the emotional impact of the experience of explicit Islamophobia. In this instance, it is experienced as an assault on the identity of 
the woman affected (Hussain \& Bugguley, 2007). Farida was so severely affected by this that she had to consider wearing a hat, instead of the physical expression of her religious identity as a woman. However, it is not common for Muslim women to change activities and remove their hijab. For instance, Nadia was told explicitly by her Muslim peers to avoid appearing Muslim and remove her hijab. She told the following story:

One of my friends, she's just like, "Nadia, yo, the Trump has been happening, Islamophobia". Like, "Yeah, I know, it's a little scary". "Nadia take your hijab off, don't worry". And that sort of throw me off. She is a Muslim, but she's like, "Take it off. God will forgive you". I was thinking, "what do you mean?" I don't think you should be afraid. I think if you are a believer, you have faith in God; that's why you're wearing it. At the same time, but just stay strong, stay true to yourself and I think, like, everything will be okay.

As it is evident in this statement, some Muslim women chose not to succumb to the fear that many Muslims in Canada found themselves confronted with. This was also described by Zainab: "it's definitely a hard thing to do. You know you will face that backlash but you do it anyways because you do it for yourself, and you're saying I want to please my creator; that's why I am wearing it. It's a good thing; you feel strong enough in your faith to wear it". Wearing the hijab meant asserting one's Muslim identity and, when asked, the participants felt that the hijab was a highly internal and personal decision, and wearing the hijab was also clearly about sending a message to everyone about who they were and what they stood for. According to Jouili (2006), in France, many Muslim women are intentionally highlighting their visibility to the world by putting on their hijabs. They do so in an attempt to mark and claim a presence in the public sphere" (Bayoumi, 2010). Amir-Moazami (2010) notes that the stigma attached to the hijab is turned into positive capital by young Muslim women, who declare the hijab as elements of free choice and self-respect. 


\subsection{Summary}

This chapter presented the analysis of three major themes emerging from interviews conducted with eight Muslim students from a wide range of university campuses in Ontario. The following themes and sub-themes arose from the data and informed the research questions:

(1) Islamophobia on Campus

Experiences with faculty members

\section{Interaction with Non-Muslim Students}

Student service provider-Muslim student experiences

(2) Rise in Islamophobic discourses \& Acts:

\section{Prompting strong religious Identity}

\section{Resisting and challenging Islamophobic sentiments}

(3) Gendered Islamophobia

By examining these three major themes, a greater insight has been gained as to how Muslim students negotiate their religious identities and their experiences attending institutions of higher education in the context of increasing Islamophobia. The themes mainly focused on the experiences within the educational realm, drawing on their own quotes, and the last theme pertains to gendered Islamophobia. In the Conclusion, I revisit the research questions, highlight my contribution to the field, the implications, and the limitations of the study and conclude with some final thoughts. 


\section{Discussion \& Conclusion}

\section{Chapter 5}

The purpose of this study was to obtain an in-depth understanding of Muslim students' experiences, and it examined the impact of discourses of Islamophobia in shaping the experience of Muslim students in higher education. In the post-9/11 era and rise of anti-Muslim bigotry, Muslim students deserve special attention and support.

This project utilized a case-study qualitative research method, and attempted to answer the following research questions: What are the experiences of Muslim Canadians attending institutions of higher education in the current context of increasing Islamophobia? How is the rising anti-Muslim sentiment impacting the academic performance of Muslim students? How do Muslim students negotiate or navigate their identities in the context of recent national and international tragic events (i.e. Paris Attacks, San Bernardino and other terrorist atrocities)? This chapter is divided in the following sections: (a) Revisiting the research question, (b) contribution to the field, (c) limitations of the research, and (d) implications for policy-making and future research.

\subsection{Research Questions Revisited}

This section will describe how the findings addressed the research question. A qualitative research case study methodology was used to investigate the following research question: (1) What are the experiences of Muslim Canadians attending institutions of higher education in the current context of rising Islamophobia? In addition, the research also addressed two sub-questions: (2) How is the rising anti-Muslim sentiment impacting the academic performance of Muslim students? and (3) How do Muslim students negotiate or navigate their identities subsequent to recent national and international tragic events? 
It was evident through the data obtained from this study that Islamophobia had a significant impact on students' experiences in higher education. This study focused primarily on the students' experiences within the educational realm that involved interactions between participants and faculty, peers, and student service providers. Muslim students reported experiences of both latent and overt Islamophobia on campus; however subtle, anti-Muslim sentiment was also present in the classroom. They also reported feeling uncomfortable walking into or sitting in the classroom, especially if they were the only person of colour, or one of a few Muslim individuals. Students' experiences of higher education revealed that they were often isolated and subjected to an 'Othering' process both as individuals amongst predominately white students and as students being taught by predominately Caucasian professors. There is often an antiMuslim backlash in the wake of terrorist attacks. Consequently, Muslim students often had to confront racist and Islamophobic comments from lecturers and non-Muslim students that espouse such views that marginalize an entire faith. Thus, Muslim students were forced into a position to defend and clarify their faith, and continuously defy and expose deep-seated prejudices. This demonstrates how educational institutions are not insulated from wider global events that may provoke racist or Islamophobic incidents on campus. In light of the literature review of the experiences of Muslim students in the U.K. and continental Europe as well as findings of this study, I would argue that Islamophobia transcends geographical boundaries. Several participants I interviewed also expressed this concern. Aisha states, "Canadians are very good at hiding their Islamophobia and that has changed now. I don't know why [it] has changed, but more people are feeling...they are empowered to come out and be racist a little bit more. 
They're embolden[d] to do these types of things". This could be related to recent events and the hate-filled agenda of the new U.S. President, who gave license to individuals to spew hate against Muslims. Local instances of racial and religious harassment are enactments of responses to events that might seem quite remote. However, dominant representations of Muslims in the media provide the justifications for Islamophobic actions (Hussain \& Bagguley, 2007). Furthermore, Muslim students' academic performance was not significantly different than their counterparts, but professors' biases and stereotypes impact students' educational experiences. All the Muslim students encountered during the course of this research were academically driven, and ambitious in terms of career plans. As one of the participants stated, "being an immigrant, and my religion, teaches me to strive and work hard, seek knowledge and encourage to pursue higher education". In addition, the hijab had a significant role in constructing Muslim female students' experiences of higher education, as they experienced more overt and explicit forms of Islamophobia. The findings of this study indicate that Muslim students were active agents and at the forefront of advocating for Muslims and actively challenging to demystify Islamophobic notions and stereotypes in pervasive forms of resistance.

The final component of the research question examined patterns of identity construction following tragic events. I conceptualized Muslim identities in the broader context of their lived experiences. A number of participants preferred self-designation of 'Muslim' as a global identity. Young Muslims are increasingly becoming devout, and have more attachment to their religious identity. Some of the participants described how their Muslim faith had grown stronger over time. Islamophobia and recent tragic events 
contributed further to generating spiritual strength among Muslims. The narratives led to a discussion of the politics associated with identity formation in relation to being a Muslim. Islamophobia motivates unity among Muslim communities: "it makes us unified, bring us together against horrible incidents." Muslims united against Islamophobia, which solidified their Islamic identity even further. Most of the participants claim their identity is "firmer, stronger" and their "spirituality is more intact". The participants were aware of the misconceptions held by the general public about Muslims and Islam, as demonstrated by various representations in the media and through their personal interactions with colleagues, friends, classmates, etc. Therefore, participants felt that there was a demand for response and apology, and they felt a need to reach out to non-Muslims in the form of dialogue, creating awareness, being vocal, and educating the public. Furthermore, this study reveals Islamophobia has adversely affected the Muslim community, including further isolation, fear of surveillance, safety concerns, and feeling the necessity to preemptively alter their behavior in an effort to mitigate the possibility of violence, to name just a few.

\subsection{Contribution to the field}

This study extends the empirical scope and expands the knowledge about Muslim students' experiences in higher education, and offers insight into their identity construction. It provides a nuanced analysis of the ways in which Muslim students respond to Islamophobia. It is my hope that the findings generated from this research will inform the academic communities, and influence future policy making in the area of educational leadership to support Muslim students in higher education. 


\subsection{Limitations of the Research}

There are several limitations in this study, and one of them is due to the nature of case-study research. First, there is relatively a small sample of Muslim students, which limits the generalizability of the findings. The sample is designed to take an in-depth examination at the experiences and interpretations of young Canadian Muslims in the post-9/11 era. I have attempted to use maximum variation strategy (Patton, 2002). I was somewhat successful in recruiting a diverse sample of participants, and made an effort to include Muslims from a variety of ethnic backgrounds and different institutions of higher education. The students interviewed represent a cross section of the Muslim communities, and include individuals from the following countries: Pakistan, Afghanistan, Somalia, and Sri-Lanka. Participants ranged in age from 19 to 26, and six females were interviewed along with two males. There was a variety of types and levels of religious ideology and practice among my research participants, yet all self-identified as Muslim (3 veiled students compared to 3 unveiled students, and 2 male students). I intentionally did not want to put a heavy weight on the hijab, since my study sought to broaden the scope by including the voices of both veiled and non-veiled Muslim females.

Future research should include a larger and more diverse group of participants. Investigating a larger sample could generate more relevant data and offer a broader focus on the challenges faced by Muslim students in Canadian universities. Furthermore, I recommend acquiring the viewpoints or voices of the professors and other important stakeholders. This will provide a unique perspective with respect to establishing effective support systems to assist Muslim students, as well as providing context to understand the particular experiences of this group. 
Another limitation of my study was employing critical race theory and not to engage more systematically with theories of intersectionality in my analysis. The use of multiple theoretical frameworks in a complementary way could be useful for analyzing complex issues beyond gender and religion.

\subsection{Implications for Future Research}

I believe this research topic and the study are timely and needed, given the dramatic increase in hate crime against Muslims; that in turn indicates that Islamophobia is intensifying the degree of anti-Muslim sentiments, and a harbinger for a far more virulent Islamophobia will become increasingly apparent in our contemporary society. Conducting this research has heightened my awareness of the challenges and the negative implications of Islamophobia. Expanding research in this area is imperative, and research directed at the effective implementation of policies is direly needed.

A large number of Muslim students experience feelings of marginalization and alienation within higher educational institutions, especially those veiled Muslim women. The negative reductive stereotypes about Muslims and challenges that veiled Muslim students face in the educational settings were observed within the study. Due to the dominant discourse, which presents Muslim women as oppressed, lacking agency, incompetent, and docile, Muslim women are socially stigmatized and frequently met with prejudice in their daily interactions. These negative images are difficult to escape since Muslim women cannot conceal their identities and wearing a hijab is compounded with staring and harassment from bigots. The various acts ranged from intentional avoidance, menacing looks, to more explicit acts of prejudice such as physical attacks. Even with obstacles they face, Muslim women are strong in the face of Islamophobia, determined to 
erase stereotypes and to practice agency (Rahmath et al., 2016). This study aimed to show the stereotypes Muslim women face and to recognize the prejudice they face in Canada.

The participants articulated the burden of responsibility to take an active role in combatting Islamophobia. There is somehow a correlation implied between terrorist events and Muslims: an onus is placed on Muslims to condemn the terrorist, or else they are assumed complicit in it. The time and energy that these students dedicated to educating others and to challenge preconceived notions and prevailing Islamophobia within higher educational institutions could be more effectively devoted to their studies. By focusing on Muslim university students, this research aimed at demystifying the complex experiences of this marginalized group in the context of escalating Islamophobia, and to raise awareness about their challenges within Canadian higher educational institutions. Professors must be aware that there are various sensitivities associated with being a Muslim amid today's context of escalating Islamophobia. Implementing an improved mechanism that supports equity initiatives is necessary. I have observed that there is little training to encourage professors in teaching equitably and to challenge their preconceived internal biases. It is important for the higher educational institutions to acknowledge and address these issues that may adversely affect the Muslim student body. The findings of this study have significant implications for policy makers at the higher education level by informing university authorities and policy makers about the challenges that this marginalized group faces in Canadian universities. In addition, there are broader policy implications as well, which stem from this research, such as the concern of lack of intervention indicated by the Muslim students interviewed in this study. 


\subsection{Summary}

This chapter framed the findings of the study, supporting research questions and highlighting the contributions of this study. Further, the limitation, implications, and areas for further research were also discussed. 


\section{Bibliography}

Abu-Ras, W. M., \& Suarez, Z. E. (2009). Muslim Men and Women's Perception of Discrimination, Hate Crimes, and PTSD Symptoms Post 9/11. Traumatology, 15(3), 48-63.

Afshar, H., Aitken, R., \& Franks, M. (2005). Feminisms, Islamophobia and identities. Political Studies, 53(2), 262-283.

Alfred, M. (1997). A re-conceptualisation of marginality: perspectives of African American female faculty in the white academy, Paper presented at SCUTREA conference 'Crossing Borders, Breaking Boundaries: Research in the Education of Adults', 1-3/7/1997, University of London.

Ali, S. R., \& Bagheri, E. (2009). Practical suggestions to accommodate the needs of Muslim students on campus. New Directions for Student Services, 2009 (125), 4754.

Allen, C. (2010). Contemporary Islamophobia Before 9/11: A Brief History. Arches Quarterly, 4(7), 14-22.

Amir-Moazami, S. (2010). Avoiding "Youthfulness?": Young Muslims negotiating gender and citizenship in France and Germany. Being Young and Muslim: New Cultural Politics in the Global South and North, 189.

Aslam, M. (2011). Muslim Pakistani-Canadian women's experiences in Canadian higher education: A case study at one Ontario university campus. Available from ProQuest Dissertations \& Theses Global.

Bagguley, P., Hussain, Y., \& Joseph Rowntree Foundation. (2007). The role of higher education in providing opportunities for South Asian women. Bristol: The Policy Press.

Bayat, A., \& Herrera, L. (2010). Being young and Muslim: New cultural politics in the global South and North. Oxford; New York: Oxford University Press.

Bayoumi, M. (2010). The God that Failed: The Neo-Orientalism of Today's Muslim Commentators. In A. Shryock (ed.) Islamophobia/Islamophilia: Beyond the Politics of Enemy and Friend. Bloomington and Indianpolis: Indiana University Press.

Bird, J. (1996). Black students and Higher Education: Rhetorics and Realities. Buckingham: Open University.

Bleich, E. (2011). What is Islamophobia and how much is there? Theorizing and measuring an emerging comparative concept. American Behavioral Scientist, 55(12), 1581-1600.

Bloul, R. A. D. (2008). Anti-discrimination laws, Islamophobia, and Ethnicization of Muslim identities in Europe and Australia. Journal of Muslim Minority Affairs, 28 (1), 7-25.

Borell, 1, K. (2015). When is the time to hate? A research review on the impact of dramatic events on Islamophobia and Islamophobic hate crimes in Europe. Islam and Christian-Muslim Relations, 26(4), 409-421.

Boysen, G. A., Vogel, D. L., Cope, M. A., \& Hubbard, A. (2009). Incidents of bias in college classrooms: instructor and student perceptions. Journal of Diversity in Higher Education. 5, 87-102. 
Brannick, T. and Coghlan, D. (2007) In Defense of Being "Native"; The Case for Insider Academic Research. Organizational Research Methods, 10, 1, 59-74.

Brunet, C. (2013). Embracing Islam in the age of terror: Post $9 / 11$ representations of Islam and Muslims in the United States and personal stories of American converts.

Bullock, K. (2002). Rethinking Muslim women and the veil: Challenging historical \& modern stereotypes. Herndon, VA: International Institute of Islamic Thought.

Butler, C. (1999). Culrural diversity and religious conformity: Dimensions of social change among secondgeneration Muslim women. In Barot, R. Bradley, H. \& Fenton, S. Ethnicity, gender and social change (Eds.) (pp. 135-151). Great Britain: Macmillan Press LTD.

Carr, M. (2006). "You Are Now Entering Eurabia.” Race \& Class 48 (1): 1-22.

Carter, J., Fenton, S., \& Modood, T. (1999). Ethnicity and Employment in Higher Education, London: Policy Studies Institute.

Chavez, C. (2008). Conceptualizing from the inside: Advantages, complications, an demands on insider positionality. The Qualitative Report, 13, 474-494.

Cole, D., \& Ahmadi, S. (2010). Reconsidering campus diversity: An examination of Muslim students' experiences. The Journal of Higher Education, 81 (2), 121-139.

Cole, M. and A. Maisuria (2009) 'Racism and Islamophobia in Post 7/7 Britain: Critical Race Theory, (Xeno-)Racialization, Empire and Education: A Marxist Analysis', in D. Kelsh, D. Hill and S. Macrine (eds) Teaching Class: Knowledge, Pedagogy, Subjectivity. New York: Routledge.

Creswell, J.W. (2007). Qulitative inquiry \& research design: Choosing among five approaches $\left(2^{\text {nd }}\right.$ ed). Thousand Oaks, CA: Sage.

Creswell, J.W. (2013). Qualitative Inquiry \& Research Design: Choosing Among Five Approaches $\left(3^{\text {nd }} e d\right)$. Thousand Oaks, CA: Sage.

Dei, G. J. S. (1997; 2000). Reconstructing 'dropout': A critical ethnography of the dynamics of black students' disengagement from school. Buffalo; Toronto: University of Toronto Press.

DeLyser, D. (2001). “Do you really live here?” Thoughts on insider research. Geographical Review, 91(1/2), 441-453.

Eisenstein, H. (2002). Globalization and the events of September 11, 2001. Socialism and Democracy, 16(1), 131-136.

Esposito, J. L., and Kalin, I. (2011) Islamophobia : the challenge of pluralism in the 21st Century. Oxford; New York, N.Y: Oxford University Press.

Feagin, J. R., Vera, H., \& Imani, N. (1996). The agony of education: Black students at White colleges and universities. New York: Routledge.

Gardner, K. \& Shukur, A. (1994). I'm Bengali, I'm Asian, and I'm living here. In R. Ballard (ed) Desh Pardesh: The South Asian Presence in Britain,. UK: C. Hurst \& Co.

Garner, S., \& Selod, S. (2015). The racialization of Muslims: Empirical studies of Islamophobia. Critical Sociology, 41(1), 9-19.

Geaves, R. et al. (2004). Islam \& The West Post 9/11. Burlington, VT; Aldershot, UK;: Ashgate Publication.

Gregory, A. (2014). Negotiating Muslim womanhood: The adaptation strategies of international students at two American public colleges. 
Gibson, M. A. (1988). Accommodation without assimilation: Sikh immigrants in an American High School. Ithaca: Cornell University Press.

Haddad, Y. Y. (2001). Muslims in U.S. politics: Recognized and integrated, or seduced and abandoned? SAIS Review 21(2), 91-102.

Hall, S. (1996). Who needs identity. In Hall, S. \& Gay, P. (Eds.). Questions of cultural identity. London. Thousand Oaks. New Delhi: Sage publications.

Harwood, S. A., Choi, S., Orozco, M., Browne Hunt, M., \& Mendenhall, R. (2015). Racial microaggressions at the University of Illinois at Urbana-Champaign: Voices of students of color in the classroom. University of Illinois at UrbanaChampaign.

Henry, F., \& Tator. C. (2009). Theoretical perspective and manifestations of racism in the academy. p. 22- 59. In Racism in the Canadian university: Demanding social justice, inclusion, and equity (pp. 22-59). Toronto: University of Toronto Press.

Hill Collins, P. (2010). Toward a new vision: Race, class, and gender as categories of analysis and connection. In R. F. Plante \& L. M. Maurer (Eds.), Doing gender diversity: Readings in theory and real-world experience, (pp. 20-32). Boulder, CO: Westview Press.

Horwedel, D. (2006). Opening eyes and minds. Diverse Issues in Higher Education. 23 (7), 14-19.

Housee, S. (2010). When silences are broken: An out of class discussion with Asian female students. Educational Review, 62(4), 421-434.

Housee, S. (2012). What's the point? Anti-racism and students' voices against Islamophobia. Race Ethnicity and Education, 15(1), 101-120.

Hussain, Y., \& Bagguley, P. (2007). Moving on up: South Asian women and Higher Education. Sterling, VA; Stoke on Trent, UK; Trentham Books.

Jacobson, J. (1997). Religion and Ethnicity: Dual and alternative sources of identity among young British Pakistanis. Ethnic and Racial Studies, 20(2), 238256.

Kaya, S. (2015). Islamophobia in Western Europe: A comparative, multilevel study. Journal of Muslim Minority Affairs, 35(3), 450-465.

Khamehi, B. (2015) Globalization and Islamophobia. International Journal Review in Life Science, 5(1), 103-110.

Khan, S. (2002). Aversion and Desire: Negotiating Muslim Female Identity in the Diaspora. Toronto: Women's Press.

Khan, S. (2009). Integrating identities: Muslim American Youth Confronting Challenges and Creating Change. In Sensoy, O. \& Stonebanks, C. (Eds.). Muslim voices in school: Narratives of identity and pluralism, (pp. 27-40). Rotterdam, The Netherlands: Sense Publications.

Kwan, M.-P. (2008). From oral histories to visual narratives: Re-presenting the postSeptember 11 experiences of the Muslim Women in the USA. Social and Cultural Geography, 9, 653-669.

Larsson, G. (2005). The impact of global conflicts on local contexts: Muslims in Sweden after 9/11 - the rise of Islamophobia, or new possibilities?. Islam and ChristianMuslim Relations, 16(1), 29-42.

Mac an Ghaill, M., \& Haywood, C. (2015). British-born Pakistani and Bangladeshi young men: Exploring unstable concepts of Muslim, Islamophobia and racialization. Critical Sociology, 41(1), 97-114. 
Mac an Ghaill, M., \& Haywood, C. (2017). Muslim students, education and Neoliberalism: Schooling a 'suspect community'. London, England: Palgrave Macmillan.

Maira, S. (2009). Missing: Youth, citizenship, and empire after 9/11. Durham: Duke University Press.

Malik, M. (2010). Anti-Muslim prejudice: Past and present. London: Routledge.

Martino, W., \& Rezai-Rashti, G. M. (2008). The politics of veiling, gender and the Muslim subject: On the limits and possibilities of anti-racist education in the aftermath of September 11. Discourse: Studies in the Cultural Politics of Education, 29(3), 417-431.

Mir, S. (2011). 'Just to make sure people know I was born here': Muslim women constructing American selves. Discourse-studies in the Cultural Politics of Education, 32(4), 547-563.

Mir, S. (2014). Muslim American women on campus: Undergraduate social life and identity. Chapel Hill: The University of North Carolina Press.

Modiri, J. (2012). The colour of law, power and knowledge: Introducing Critical Race Theory in (post-) apartheid South Africa. South African Journal on Human Rights, 28 (3), 405-436.

Moghissi, H. (2009). In Rahnema S., Goodman M. J. (Eds.), Diaspora by design: Muslims in Canada and beyond. Toronto: University of Toronto Press.

Mostafa, G.M.M. (2006). Learning and cultural experiences of Arab Muslim graduate students in a Canadian university. Journal of Contemporary Issues in Education, 1(1): 36-53.

Nasir, N. \& Al-Amin, J. (2006). Creating identity-safe spaces on college campuses for Muslim students. Change: the Magazine of Higher Learning, 38(2), 22-27.

Parker-Jenkins, M. (1991). Muslim Matters: The Educational Needs of the Muslim Child. New Community, 17(4), 569-582.

Patton, M.Q. (2002). Qualitative Research \& Evaluation Methods, Third edition. Thousand Oaks, California: Sage Publications Inc.

Patton, M. Q. (2015). Qualitative research \& evaluation methods: Integrating theory and practice (Fourth ed.). Thousand Oaks, California: SAGE Publications, Inc.

Perry, B. (2014). Gendered Islamophobia: Hate crime against Muslim women. Social Identities, 20 (1), 74-89.

Rahman, M. S. (2007). Transnational media reception, Islamophobia, and the identity constructions of a non-Arab Muslim diasporic community: The experiences of Bangladeshis in the united states since 9/11. Southern Illinois University at Carbondale. ProQuest Dissertations and Theses,303.

Rahmath, S., Chambers, L, \& Wakewich, P. (2016). Asseting citizenship: Muslim women's experiences with the hijab in Canada. Womens Studies International Forum, 58, 34-40.

Rana, J., \& Rosas, G. (2006). Managing crisis. Cultural Dynamics, 18(3), 219-234.

Rida, Z. T. (2004). Muslim women reflecting on American education: Exploring the question of educational identity. Available from ProQuest Dissertations \& Theses Global.

Ruby, T.F. (2006). "Listening to the voices of hijab.” In, Women's Studies International Forum, 29, 54-66. 
Saeed, T. (2016). Islamophobia and Securitization: Religion, Ethnicity and the Female Voice. Switzerland: Palgrave Macmillan.

Said, E. W. (1979). Orientalism. New York: Vintage Books.

Samad, Y. (1996). The Politics of Islamic Identity among Bangladeshis and Pakistanis in Britain. In Terence, S., Ranger, Y. and Stuart, O. (eds.) Culture Identity and Politics: Ethnic Minorities in Britain. Avebury: Ashgate Publishing Ltd.

Sarwar S. \& Yasmin, N (1996). Becoming Muslim and woman: The bifurcation of self and critical multiculturalism.

Sayyid, S., \& Vakil, A. (2010). Thinking through islamophobia: Global perspectives. New York: Columbia University Press.

Schmidt, G. (2002). Dialectics of authenticity: Examples of ethnification of Islam among Young Muslims in Sweden and the United States. The Muslim World, 92(1-2), 117.

Shain, F. (2011). New folk devils: Muslim boys and education in England. Stoke on Trent, UK: Trentham Books.

Shammas, D. S. (2009). Post-9/11 Arab and Muslim American community college students: Ethno-religious enclaves and perceived discrimination. Community College Journal of Research and Practice, 33(3-4), 283-308.

Shryock, A. (2010). Islamophobia/Islamophilia: Beyond the politics of enemy and friend. Bloomington: Indiana University Press.

Sianna, G. \& Clark, A. (1992). Muslim women in the workplace. Employee Counselling Today, 4, (5), 20.

Sirin, S. \& Fine, M. (2008). Muslim American identity understanding hyphenated identities through multiple methods. New York and London: New York University Press.

Sleeter, C. E. (2005). Un-standardizing curriculum: Multicultural teaching in the standards-based classroom. New York: Teacher College Press.

Speck, B. W. (1996). Professor bias, religion, and ESL students: The need for a reflective. pedagogy. College Student Journal, 30(3), 390.

Speck, B. W. (1997). Respect for religious differences: The case of Muslim students. New Directions for Teaching and Learning, 1997 (70), $39-46$.

St. Pierre, E. (2000). Poststructural feminism in education: An overview. International Journal of Qualitative Studies in Education, 13 (5), 477-515.

Stubbs, B. \& Sallee, M. (2013). Muslim, too: Navigating multiple identities at an American university. Equity and Excellence in Education, 46(4), 451-467.

Taras, R. (2013). 'Islamophobia never stands still': Race, religion, and culture. Ethnic and Racial Studies, 36(3), 417-433.

Tyrer, D. \& Ahmad, F. (2006). Muslim women and higher education: Identities, experiences, and prospects. A Summary Report. UK: Oxford.

Wiktorowicz, Q. (Ed.). (2004). Islamic activism: A social movement theory approach. Indiana Univ Pr.

Wilkinson, S., \& Kitzinger, C. (2013). Representing our own experience: Issues in "Insider" research. Psychology of Women Quarterly, 37(2), 251-255.

Yin, R. K. (2014). Case Study Research: Design and Methods $\left(5^{\text {th }}\right.$ ed). Thousand Oaks, CA: Sage. 
Zaal, M. (2012), Islamophobia in Classrooms, Media, and Politics. Adolescent Literacy Policy, 55 (6), 555-558.

Zine, J. (2000). Redefining resistance: Toward an Islamic sub-culture in schools. Race, Ethnicity, and Education, 3(3), 293-316.

Zine, J. (2001). Muslim youth in Canadian schools: Education and the politics of religious identity. Anthropology and Education Quarterly, 34(2), 399-423.

Zine, J. (2003). Dealing with September 12th: The challenge of anti-Islamophobia education, 33(3).

Zine, J. (2006). Unveiled sentiments: Gendered Islamophobia and experiences of veiling among Muslim girls in a Canadian Islamic school. Equity \& Excellence in Education, 39(3), 239-252. 


\section{Appendix 1: Letter of Information}

Project Title: Impact of Islamophobia on Post-Secondary Muslim Students in a Canadian University

Document Title: Letter of Information and Consent-Student

Principal Investigator + Contact: Professor Goli Rezai-Rashti, PhD

Faculty of Education, Western University,

\section{Invitation to Participate}

My name is Hassina Alizai and I am a Master of Education student at the Faculty of Education, the University of Western Ontario. I am conducting research that will investigate the experiences of Muslim students attending institutions of higher education in the context of increasing Islamophobia. I am inviting Muslim students between the ages of 18 to 30, who are attending a post-secondary institution in Canada to participate in this study.

Why is this study being done?

The purpose of this study is to obtain an in-depth understanding of Muslim students' experiences and examine the impact of discourses of Islamophobia in shaping the experience of Muslim students in higher education.

\section{Inclusion Criteria}

Young Canadian Muslims, who are attending a post-secondary institution in Canada, will be those eligible to participate in this study. The participants can be male or female between the ages of 18 and 30 .

\section{How long will you be in this study?}

There will be one interview during your participation in this study and the interview will take approximately 45-60 minutes.

\section{What are the study procedures?}

If you agree to participate, you will be asked to participate in forty-five minutes to an hour-long semi-structured digitally recorded interview. You can still participate if you do not agree to be recorded. The interview will be conducted in a mutually agreed upon location.

\section{What are the risks and harms of participating in this study?}

There are no known or anticipated risks or discomforts associated with participating in this study. However, as this study is about Islamophobia, it is possible that some level of emotion will arise while discussing negative aspects of your experience as a Muslim student in Canada. If this happens and you feel any discomfort with the interview, you can stop participating at any time in the process. In addition, if you become distressed, resources for counseling will be made available to you. 


\section{What are the benefits of participating in this study?}

You may not directly benefit from participating in this study, but information gathered may provide benefits to society as a whole, as the intention of this research is to investigate Muslim students' experiences in the current context of Islamophobia.

\section{Can participants choose to leave the study?}

If you decide to withdraw from the study, you have the right to request withdrawal of the information collected about you. If you request the removal of your personal information, that request will be honoured.

\section{How will participants' information be kept confidential?}

There will be no inclusion of your name, which may have allowed some to link the data and identify you. I will honour your privacy by protecting anonymity and giving you a pseudonym. Representatives of The University of Western Ontario Non-Medical Research Ethics Board may require access to your study-related records to monitor the conduct of the research. While we do our best to protect your information, there is no guarantee that we will be able to do so. If data is collected during the project, which may be required to report by law we have a duty to report. All data that will be collected will be destroyed in five years, all data stored on electronic devices will be deleted and any paper copies will be shredded. A list linking your study number with your name will be kept by the researcher in a secure place, separate from your study file. If the results of the study are published, your name will not be used.

\section{Are participants compensated to be in this study?}

You will not be compensated for your participation in this research.

\section{What are the rights of participants?}

Your participation in this study is voluntary. You may decide not to be in this study. Even if you consent to participate, you have the right to not answer individual questions or to withdraw from the study at any time. If you choose not to participate or to leave the study at any time, it will have no effect on your academic standing. You do not waive any legal right by consenting to this study.

\section{Whom do participants contact for questions?}

If you have questions about this research study, please contact Hassina Alizai at , or Professor Goli Rezai-Rashti, Principle Investigator at . If you have any questions about your rights as a research participant or the conduct of this study, you may contact The Office of Human Research Ethics (519) 661-3036, email: ethics@uwo.ca. 


\section{This letter is yours to keep for future reference. Appendix 2: Consent Form}

Project Title: Impact of Islamophobia on Post-Secondary Muslim Students in a Canadian University

Principal Investigator + Contact: Professor Goli Rezai-Rashti, PhD

Faculty of Education, Western University.

I have read the Letter of Information, have had the nature of the study explained to me and I agree to participate. All questions have been answered to my satisfaction.

I agree to be audio / video-recorded in this research

\section{YES NO}

I consent to the use of unidentified quotes obtained during the study in the dissemination of this research.

\section{YES NO}

Print Name of Participant

Signature

Date (DD-MMM-

$Y Y Y Y)$

My signature means that I have explained the study to the participant named above. I have answered all questions.

Print Name of Person

Obtaining Consent
Signature

Date (DD-MMM-

$Y Y Y Y$ ) 


\section{Curriculum Vitae}

Name:

Post-secondary Education and Degrees:

\section{Related Work Experience}

Hassina Alizai

The University of Western Ontario

Bachelor of Arts (Honours), Double Major in Criminology and Political Science

2009-2013

University of Toronto

Bachelor of Education, Intermediate/Secondary

2013-2014

The University of Western Ontario

Master of Education

Thesis Supervisor: Prof. Goli Rezai-Rashti

2015-2017

Global Perspectives \& Project Work Teacher

Nazarbayev Intellectual School of Physics and Mathematics,

Kazakhstan

2014-2015

Research Assistant

The University of Western Ontario

Research Project: Next Generation Learning in AMDSB

2015-2016

Occasional Teacher

Thames Valley District Board

2016-Present 